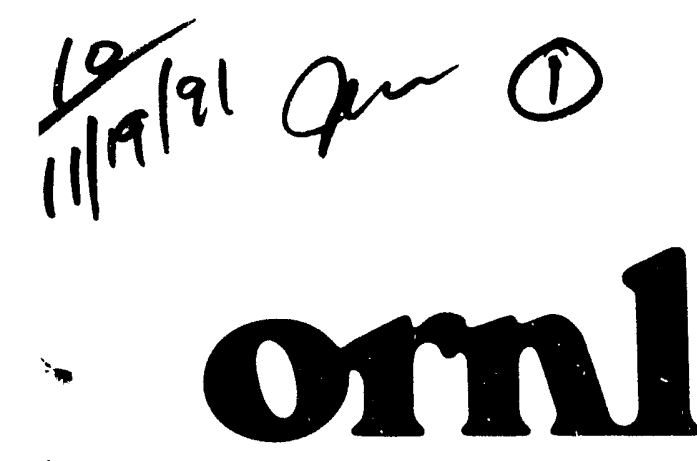

OAK RIDGE NATIONAL LABORATORY

MARTIN MARUETTA
ORNL/TM-11788

\section{Rereved by 09}

NOV 191991

Energy Security, Public Policy, and the Role of the DOE Office of Energy Emergencies

David J. Bjornstad

T. Randall Curlee

Douglas R. Bohi 
This report has been reproduced directly from the best available copy.

Available to DOE and DOE contractors from the Office of Scientific and Technical Information, P.O. Box 62, Oak Ridge, TN 37831; prices available from (615) 576-8401, FTS 626-8401.

Available to the public from the National Technical Information Service, U.S. Department of Commerce, 5285 Port Royal Rd., Springfield, VA 22161.

This report was prepared as an account of work sponsored by an agency of the United States Government. Neither the United States Government nor any agency thereof, nor any of their employees, makes any warranty, express or implied, or assumes any legal liability or responsibility for the accuracy, completeness, or usefulness of any information, apparatus, product, or process disclosed, or represents that its use would not infringe privately owned rights. Reference herein to any specific commercial product, process, or service by trade name, trademark, manufacturer, or otherwise, does not necessarily constitute or imply its endorsement, recommendation, or favoring by the United States Government or any agency thereof. The views and opinions of authors expressed herein do not necessarily state or reflect those of the United States Government or any agency thereof. 


\title{
ENERGY SECURITY, PUBLIC POLICY, AND THE ROLE OF
}

\section{THE DOE OFFICE OF ENERGY EMERGENCIES}

\author{
David J. Bjornstad \\ T. Randall Curlee \\ Energy and Economic Analysis Section \\ Energy Division \\ and
}

Douglas R. Bohi

Resources for the Future

Washington, D.C. 20036

Prepared by the

OAK RIDGE NATIONAL LABORATORY

Oak Ridge, Tennessee 37831 managed by

MARTIN MARIETTA ENERGY SYSTEMS, INC.

for the

U.S. DEPARTMENT OF ENERGY

under Contract No. DE-AC05-84OR21400

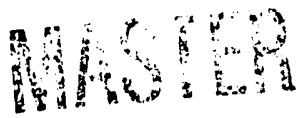


LIST OF FIGURES $\ldots \ldots \ldots \ldots \ldots \ldots \ldots \ldots \ldots \ldots \ldots \ldots \ldots \ldots \ldots \ldots \ldots$

LIST OF TABLES $\ldots \ldots \ldots \ldots \ldots \ldots \ldots \ldots \ldots \ldots \ldots \ldots \ldots \ldots \ldots \ldots \ldots \ldots \ldots$

EXECUTIVE SUMMARY $\ldots \ldots \ldots \ldots \ldots \ldots \ldots \ldots \ldots \ldots \ldots \ldots \ldots \ldots$ vii

1. INTRODUCTION $\ldots \ldots \ldots \ldots \ldots \ldots \ldots \ldots \ldots \ldots \ldots \ldots \ldots \ldots \ldots \ldots \ldots \ldots \ldots$

2. AN ENERGY EMERGENCY POLICY ANALYSIS FRAMEWORK $\ldots \ldots \ldots \ldots \ldots$

2.1. AN ENERGY EMERGENCY DEFINED $\ldots \ldots \ldots \ldots \ldots \ldots \ldots \ldots \ldots, 3$

2.2. THE U.S. ENERGY SYSTEM $\ldots \ldots \ldots \ldots \ldots \ldots \ldots \ldots \ldots \ldots \ldots, 5$

2.3. TYPES OF ENERGY EMERGENCIES $\ldots \ldots \ldots \ldots \ldots \ldots \ldots \ldots \ldots \ldots, \quad 9$

2.3.1. TECHNICAL CONSTRAINTS $\ldots \ldots \ldots \ldots \ldots \ldots \ldots \ldots \ldots, 10$

2.3.2. CHANGES IN MARKET STRUCTURE $\ldots \ldots \ldots \ldots \ldots \ldots \ldots \ldots, 10$

2.3.3. CHANGES IN EXTERNAL POLITICAL CONDITIONS ......... 11

2.3.4. CHANGES IN REGULATORY AND INSTITUTIONAL CONSTRAINTS ............................ 12

2.3.5. SUDDEN CHANGES IN EXTERNALITIES ASSOCIATED WITH ENERGY PRODUCTION AND USE $\ldots \ldots \ldots \ldots \ldots \ldots \ldots \ldots, 12$

2.4. ECONOMIC GOALS AND ENERGY EMERGENCIES $\ldots \ldots \ldots \ldots \ldots \ldots 14$

3. OPTIONS, TRADEOFFS, AND THE ROLE OF GOVERNMENT IN ENERGY

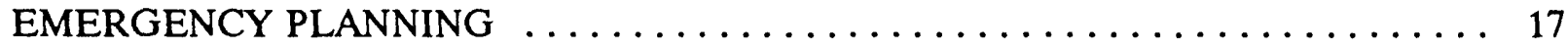

3.1. MAKING THE ENERGY SYSTEM MORE RESILIENT TO ENERGY

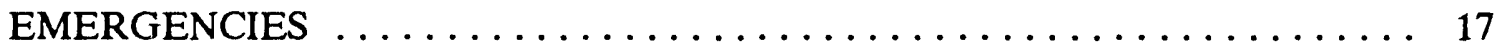

3.1.1. FLEXIBILITY ON THE SUPPLY AND DEMAND SIDES ........ 17

3.1.1.1. Surge Production Capacity . . . . . . . . . . . . . . . 18

3.1.1.2. Flexible Production and Transportation Capacities ......... 18

3.1.1.3. Fuel-Switching Capacity $\ldots \ldots \ldots \ldots \ldots \ldots \ldots \ldots \ldots \ldots \ldots \ldots$

3.1.1.4. Institutional and Regulatory Flexibility ............. 19

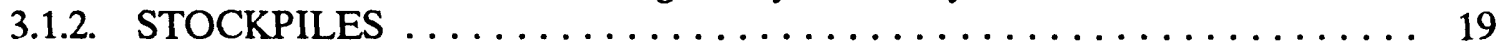

3.1.3. CONTINGENCY PLANNING BY GOVERNMENT ........... 20

3.2. THE GOVERNMENT'S ROLE IN ENERGY EMERGENCIES $\ldots \ldots \ldots \ldots$ 2u

3.2.1. WHY GOVERNMENT INVOLVEMENT? $\ldots \ldots \ldots \ldots \ldots \ldots \ldots, 20$

3.2.1.1. Externalities ....................... 21

3.2.1.2. Failures with Respect to Information and Uncertainty ...... 21

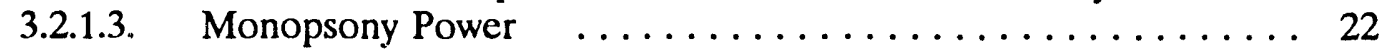

3.2.2. WHAT CAN GOVERNMENT DO? $\ldots \ldots \ldots \ldots \ldots \ldots \ldots \ldots, 22$

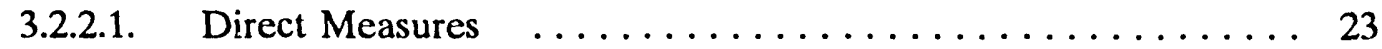

3.2.2.2. Indirect Measures ......................... 23

3.2.3. THE LIMITS OF GOVERNMENT ACTIONS ................ 24

3.3. ENERGY SECURITY AND ENVIRONMENTAL TRADEOFFS $\ldots \ldots \ldots \ldots 24$

3.4. SHOULD GOVERNMENT INTERVENE? $\ldots \ldots \ldots \ldots \ldots \ldots \ldots \ldots \ldots$ 


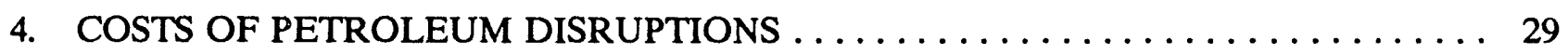

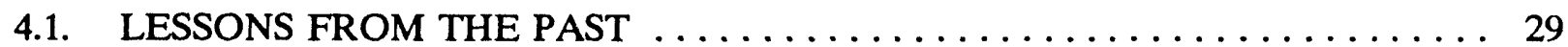

4.2. COSTS AND POLICY OPTIONS $\ldots \ldots \ldots \ldots \ldots \ldots \ldots \ldots \ldots \ldots \ldots \ldots \ldots$

4.3. ISSUES CONCERNING THE SIZE AND USE OF THE SPR $\ldots \ldots \ldots \ldots \ldots 33$

4.4. THE IMPORTANCE OF INTERNATIONAL COOPERATION $\ldots \ldots \ldots \ldots \ldots 34$

5. RELEVANCE FOR THE OFFICE OF ENERGY EMERGENCIES $\ldots \ldots \ldots \ldots \ldots 37$

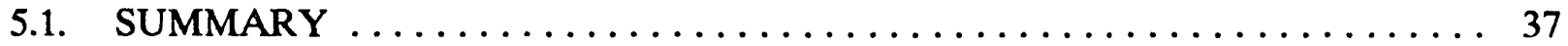

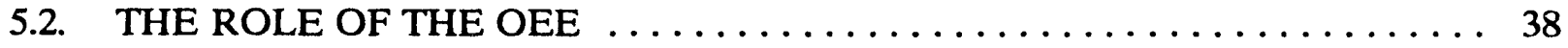

5.3. IMPLICATIONS FOR OEE PLANNING $\ldots \ldots \ldots \ldots \ldots \ldots \ldots \ldots \ldots \ldots \ldots$ 
Figure 1. The Domestic Energy Ststem $\ldots \ldots \ldots \ldots \ldots \ldots \ldots \ldots \ldots \ldots \ldots \ldots$

\section{LIST OF TABLES}

Table 1 . Energy consumption by primary fuels (quadrillion $\mathrm{Btu}) \ldots \ldots \ldots \ldots \ldots$ 


\section{EXECUTIVE SUMMARY}

This paper addresses the concept of energy security, the costs and benefus of energy security, and policies which could potentially alter these casts and benefits. These issues are considered from the perspective of the Department of Energy's Ofjice of Energy Emergencies, with the goal of determining if alterative or additional roles should be open to this Office. The approach taken is limited to the economic costs and benefits of energy security, reflecting our view that the bulk of important energy security issues can at least be approached from this perspective.

We begin by defining a generic energy emergency, one that can be applied to virtually all energy forms and which includes most circumstances that would commonly be thought to constitute an emergency. In our view an energy emergency results from a sudden change in the quantity, market price, and/or social value of energy, in combination with a domestic and/or world wide energy system that cannot rapidly adjust to that change. The definition is carefully stated, because we do not believe that mitiguting the impacts of such events is always necessary, nor that it is uniquely a governmental responsibility. In fact, the first recourse in emergency preparedness should always be to the private sector. Further, if the private sector does not appear to adequately prepare, there must be justification before public actions can be undertaken. However, there are many varieties of situations which can give rise to energy emergencies, and there are many reasons why government should intervene to mitigate impacts of energy emergencies.

In particular, government should deal with three different aspects of emergency energy activities. First, it should condition the decision making environment by seeing that adequate information about energy conditions is available and that its own policy position is clear. Next, government should evaluate the preparedness measures undertaken by the private sector. In doing this, government should apply two measures -- efficiency and equity. In the efficiency measure, it seeks to determine whether or not businesses and consumers have adequately assessed the tradeofss between the current costs which must be accepted in exchange for uncertain future benefis if an energy emengency occurs. In applying the equity measure, government must satisfy itself that the burdens of an emergency are not distributed unfairly. Ultimately, government must try to integrate policies that seek efficiency and equity into the context of national economic well being. If the assauls caused by the emengency is of small consequence, inaction may suffice. Finally, if it finds private sector preparation to be inadequate, government has a variety of direct and indirect means with which to intervene. One direct measure currently used is the buildup and drawdown of the strategic petroleum reserve (SPR). Others include contingency plans to override market allocations during wartime, as might be developed under the graduated mobilization response (GMR). Indirect means include a variety of tax and transfer schemes that alter existing private sector incentives to prepare. Well conceived monetary and fiscal policies complete the tools.

Applying these tools is a separate matter. Policy may allow prices to rise and markets forces to allocate shorfalls, or policy may call for government actions to override market allocations. First recourse should always be to market allocations, but as a practical matter equity effects will always be considered as prices rise. Policies in which government relies totally on government allocations should be reserved for extraordinary circumstances. 
In considering new emergency policy initiatives, government should incorporate the impacts on its other policy responsibilities, such as environmental degradation. Policy makers should realize that their ability to ameliorate impacts is limited For individuals, burdens can always be redistributed -- tax dollars can ensure that furms or families are not devastated. But, on an aggregate basis, emergencies will always impose casts, casts that can be offset somewhat by preparation, but that are increased by policies that reduce economic efficiency.

There is a considerable bady of evidence from past disnuptions in international oil markets, including the recent Iraqi invasion of Kuwait. Basically, the enengy system's ability to accommodate shocks has been improved by both private and public actions. Private actions include increased demand and supply side flexibilities, better trading institutions, including more flexible purchase arrangements and the development of a future's market. Greater exchange of ideas and coordination of policy prerogatives among governments has apparently occurred. The existence of the SPR is a furm commitment. Evidence confirms that price and quantity displacements can result from a variety of causes and that a simple view of any oil crisis is likely to be flawed. The relationship between energy prices and domestic economic reactions in different nations is uncertain; it hinges on how oil is used and how related policies are employed.

Current activities by the OEE are less broad and less focused on economic impacts than the potential implied by this review. Available new activities include expanded analytical capabilinies that would span all types of emergency circumstances, systematically record information gaps and policy prerogatives, and assert internal leadership at DOE for emergency matters. By acting as an energy security advocate, $O E E$ could influence decisions by ELA on modelling capability and data collection, the environment office on security related tradeofJs, and the technical offices on the security related implications of R\&D options. It could serve as a stronger point of contact within and without DOE on energy security matters. Having done these things, it would be a much stronger source of counsel to policy makers.

There are many barriers to accomplishing these suggestions. A starting point would be the development of a common framework for relating energy security issues to other en rogy issues and to their economic foundations. Such a framework would be broad, essentially encompassing the range of circumstances reviewed in the body of this paper, but it would not give equal weight to each Rather, it would seek to evaluate costs and benefits, focus on options, and highlight gaps in knowledge for a prioritized set of energy security issues. In doing this it would accentuate the different aspects of preparedness planning and increase OEE's focus on economic matters and the private sector. We endorse steps towand its construction. 


\section{INTRODUCTION}

The Office of Energy Emergencies (OEE) within the U.S. Department of Energy (DOE) is charged with providing expertise to formulate and evaluate polices that deal with energy emergencies. As part of its participation in the National Energy Strategy (NES) process, it has been reexamining the breadth and scope of its activities. In assisting OEE, the Oak Ridge National Laboratory (ORNL) has joined with Resources for the Future (RFF) to assess the spectrum of energy emergencies within a conceptual framework and to discuss the role of OEE in promoting energy security. This document reports the findings of the ORNL/RFF effort.

Several objectives are pursued in this document. In Section 2, we develop a policy analysis framework which taxonomizes energy emergencies, relates these to the energy system, and describes how they are related to economic policy goals. We begin in Section 2.1 with a general definition of an energy emergency which is sufficiently broad to encompasses the full range of energy emergencies -- from oil disruptions, to natural disasters, to mobilization for war. The definition serves as a benchmark from which similarities and differences among different types of energy emergencies can be identified and potential government actions can be evaluated. Next, in Section 2.2, we develop a representation of the energy system which can describe both its physical and behavioral attributes. It is used to identify points within the energy system at which emergencies can occur and the way in which ernergencies in one energy sector may affect or be dissipated by activities in other energy sectors. Section 2.3 identifies the range of constraints that can precipitate an emergency at various points in the system. Section 2.4 completes the developinent of the analytical framework, by discussing how the economic policy goals which the nation pursues are affected by energy emergencies.

The discussion in Section 3 turns to the options available for dealing with energy emergencies, the tradeoffs government must consider in defining its role in this process, and the arguments for and against government intervention. Section 3.1 examines the general options for making the energy system more resilient to the costs that typically accompany energy emergencies. These options can be pursued by either the government or the private sector. Section 3.2 addresses the role of government in promoting energy security. In that section we begin by reviewing the arguments for government intervention on grounds of economic efficiency and the equitable distribution of economic hardships. We follow with observations on the limitations of government actions. While in some cases government intervention is appropriate, intervention imposes its own costs and may duplicate or hinder private-sector activities. Government intervention cannot reduce the total costs imposed by an energy emergency below the level that would occur if markets worked perfectly, though it can alter the distribution of these costs among producing and consuming groups.

The potential tradeoffs that may exist between energy security and environmental quality are addressed in Section 3.3. Frequently, the arguments favoring government intervention to protect the environment and to mitigate energy emergencies are similar, but their outcomes may be in conflict. The objective is to find win-win measures that promote both objectives, or at minimum to identify the tradeoffs that must be made. Where conflicts cannot be resolved, the magnitude of the tradeoffs must be measured to facilitate intelligent policy decisions. Finally, in Section 3.4, the arguments for and against intervention are reviewed and summarized. 
Section 4.0 draws on our experience with oil vulnerability to illustrate the types of energy security issues discussed in previous sections. We first review the evidence available from the past 20 years and examine responses by government and business to past oil emergencies. Attention turns next to costs of oil disruptions that appear to have been thus far neglected and options for dealing with them. Particular attention is paid to the strategic petroleum reserve (SPR), because it is a major current policy response to past disruptions, and because of its relevance for events such as the Iraq/Kuwait crisis. The section closes with a discussion of the international character of oil markets and the importance of international cooperation in forming reasoned policy responses.

The report concludes in Section 5 with a summary of the assessment, an overview of the OEE, and a description of additional roles OEE could play in promoting energy security. That discussion seeks to bri..g together the general characteristics of energy emergencies and the options available in dealing with them with the limitations of government in promoting energy security. Also discussed are the general charge of the OEE within DOE with the activities it currently pursues and does not pursue. It is concluded that additional roles are open to OEE were it to pursue them. These additional roles include: (1) expanding analytical activities regarding energy vulnerabilities of all kinds and integrating into the analysis the role of the private sector in overcoming energy emergencies, (2) acting as an energy security advocate within DOE by tracking R\&D and policy initiatives by other offices and evaluating their impacts on energy security, and (3) becoming a stronger point of contact for other governmental and private groups seeking DOE data or technical expertise on matters of energy security.

We further conclude that these tasks would be facilitated by the construction of an analytical framework that would allow OEE to focus attention on public/private sector interactions, the decision making environment in which energy emergency planning is conducted, the planning and analysis that underlies decisions, and the policies that implement plans. It would permit economic efficiency and equity goals to be contrasted. Such a framework would push OEE toward additional economic analysis and build on existing strengths in emergency preparedness planning. These elements are discussed in further detail throughout the report, though the effort falls far short of providing a total framework. 


\section{AN ENERGY EMERGENCY POLICY ANALYSIS FRAMEWORK}

The purpose of this section is to provide a format for the remainder of the paper. It contains a description of energy emergencies, the points of the system at which emergencies can occur, the various causes of energy emergencies, and the impacts energy emergencies can have on economic policy goals.

\section{AN ENERGY EMERGENCY DEFINED}

For the purpose of this assessment, we define an energy emergency to result from a sudden change in the (1) quantity, (2) market price, and/or (2) social value of energy, in combination with a world and/or domestic energy system that cannot rapidly adjust or otherv ise respond to that change. Sudden in this context also suggests that the change is unexpected, in the sense that the timing of the change could not be known with any certainty. Moreover, in our terms the mere existence of an emergency does not necessarily call for government action. Such action must be based on an evaluation of the potential welfare losses that might result from the emergency and the inability of the private sector to deal with these losses efficiently or equitably. There are four aspects of our definition which determine if an event qualifies as an energy emergency.

First, an energy emergency can be precipitated by a change in quantity of energy supplied, the market price at which is traded, and/or the value which society places on an energy product over and above the price at which it is traded. A common misperception is that an energy emergency must be linked with a reduction in the quantity of energy supplied. Clearly, one sort of energy emergency occurs when a supply disruption leads either to shortfalls or a significant price jump, either or both of which can potentially impose large economic costs. Alternatively, reductions in energy supply, in combination with a price ceiling that prevents energy prices from rising, can also lead to misallocations of resources and potentially to large economic costs. It is not essential, however, that an energy emergency be linked to a change in quantity of energy supplied. As is discussed below, changes in, for example, market structure and expectations can lead to demand changes -. e.g., hoarding -- which may result in drastic changes in energy prices.

Neither is it essential that an energy emergency be precipitated by either a large change in quantity supplied or market price. As will be discussed below, the market price of energy does not always reflect the true social value of energy. For example, when environmental costs are not borne by producers, they are not reflected in the prices paid by consumers, but they are borne by third parties who suffer the affects of pollution or other social "bads." For our present purpose, we introduce the concept of a related externality, the military security externality, ${ }^{1}$ which causes market

\footnotetext{
${ }^{1}$ When the nation is at war, the social value of scarce, strategic resources, such as fuel, clearly exceeds their market value during peacetime. This social value may or may not be reflected in market price, depending upon whether or not public policy supports a market-oriented mobilization in which government bids up the price of fuels to obtain supplies, or a command system in which allocation and rationing occur. In the latter case, prices could be restrained by controls or other mechanisms, and social value would exceed market price. However, even during peacetime, there is a finite probability of war (or more precisely, of different states of military activity). The nation therefore places a premium on a secure supply of strategic fuels and values readily available fuels more than remote ones. As the state of the world changes, and the probability of conflict changes, this premium also changes, but the premium may or may not be reflected in market prices.
} 
price to differ from social value. A large change in these and possibly other externalities can result in significant changes in the social value of energy and thus precipitate an energy emergency. Price and/or quantity of energy available: for use do not necessarily have to change for the social value of energy to change. Significant changes in the social value of energy can call for emergency actions - such as pollution abatement or preparations for military mobilization. These events are appropriately listed as energy emurgencies.

Second, the definition suggests that a change in quantity, market price, and/or social value must be sudden. While we acknowledge that gradual changes in these variables may pose long-term problems -- e.g., resource depletion -- we suggest that those problems are fundamentally different than those that result from sudden changes. In particular, the appropriate responses by the public and private sectors to long-run problems differ in terms of motivation and actions. It is true that long-term trends may affect the probability and/or consequences of energy emergencies in future time periods and, therefore, long-term trends are important to monitor. Further, in some cases it may be appropriate for government to promote certain long-term trends so as to reduce the probabilities and/or consequences of future er ergy emergencies. We do not, however, subscribe to the notion that long-term trends in themselves constitute an energy emergency.

Third, the definition does not limit energy emergencies to very short-term events. A shortterm change in energy quantities, prices, and/or social value may constitute an energy emergency. Likewise, a change that occurs suddenly and is maintained over the longer term may also be an energy emergency. When, or if, the change in quantity, price, and/or social value is reversed is of less importance than the fact that initial change occurs suddenly.

Finally, a sudden change in quantity, price, and/or social value must occur in combination with a severe inability of the energy system, or important subgroups within the system, to adjust or otherwise respond to that change. In other words, the change must be unanticipated in the sense that the system has not made reasoned preparation. It is a common misperception about energy emergencies, and indeed many emergencies, that the public sector can deal with the event in such a way that society bears no costs. In fact, the public and private sectors are limited in their abilities to respond to any change, and transitional costs must be absorbed as a part of doing business in a complex interrelated society. If the energy system has correctly anticipated changes in quantities, prices, and/or social value and has made reasoned preparations the overall costs of the event will be minimized, and an energy emergency will not exist. What may exist is a "social crisis" in which subgroups of the population may bear disproportionate transitional cost, a situation we will discuss below.

Private suppliers, feeling they would be unable to profit from extraordinary investments due to price controls or other government actions during war, might fail to respond on the supply side, and military planners, believing they would somehow receive the fuels they need during conflict, would likewise neglect crisis preparations. When these conditions exist, market price falls below social value, and the difference is a social premium which is termed the military security externality. Defined in this way, this concept provides a useful analytical tool. 


\subsection{THE U.S. ENERGY SYSTEM}

There are many ways to represent the U.S. energy system, each of which emphasizes different aspects of its technical and bchavioral makeup. As has been explained, th: OEE is concerned with identifying points of vulnerability resulting from rapidly occurring supply disruptions, price changes, and changes in energy's social value, while focusing attention on the ability of the system to accommodate these changes. At the same time it is useful to incorporate aspects of economic and engineering efficiency and potential environmental assaults within a systemic framework, because to be an integral part of DOE, OEE must be able to evaluate the impacts of conservation, environmental policy and other DOE policies on its own energy security concerns.

Fig. 1 provides a view of the U.S. energy system that incorporates most of these features. Primary energy resources appear on the left-most side and final demands on the right-most. Linking primary supply and demand are a series of steps that include primary conversion, storage and transport, electrical conversion, and distribution. One can deal with engineering efficiency by moving from the left to the right of the table, and recording this movement in physical terms, such as Btu's. Hence, coal may be converted to electricity with accompanying efficiency loss and then used in an electrical motor at nu conversion loss, or it can be burned in an industrial boiler with accompanying loss. At any point, one can investigate the role of technology in effecting efficiency by comparing conversion losses or environmental loadings. A distinctive feature of the energy system is its capital intensity and the inflexibility capital intensity implies.

However, it is insufficient to view the energy system merely as a capital network, much like. the body's circulatory system, in which raw energy services are pumped in at one side in aggregate form, disperse and co-mingle through a capillary-like system, and enierge at the far side as aggregate energy services. While valuable, such a representation fails to highlight that at each link and node, individual decision-making agents affect the conditions under" which energy' products will be bought and sold. These agents arc diverse in size, character, and motivation, ranging from OPEC to domestic wildcatters, government regulators to union bargaining agents, and massive end users (e.g., DoD procurement) to individual households. These agents present the potentiai to generate a variety of circumstances that could disrupt the energy system.

Economic efficiency is incorporated as a flow of dollars per unit energy, typically from the right portion of the table where final demands occur, to the left part where basic energy resources are supplied. Each node in the table can be viewed as a market, characterized by supply and demand conditions, and yielding ruarket clearing quantities and prices. These "prices" can be compared as marginal costs and can be thought of as the "competition" for other sorts of substitutable energy forms. Whereas Btu's incoiporate the physical attribute of the energy type to do work, prices incorporate the additional costs (value added) associated with capital investment, labor, and other factor inputs. As we discuss below, decision makers also form expectations regarding risk and uncertainty and incorporate price premiums on top of direct marginal costs to reflect flexibility in the energy system. When these premiums are incorporated into market prices, they are said to be internalized by the market and are simply referred to as private costs. In addition to the private marginal costs that the system generates as energy prices and which reflect private valuations of energy source, social valuations may also be incorporated by adding price increments for environmental or energy security externalities. In this way, when the discussion turns to potential government policy alternatives, least cost solutions can be compared. 


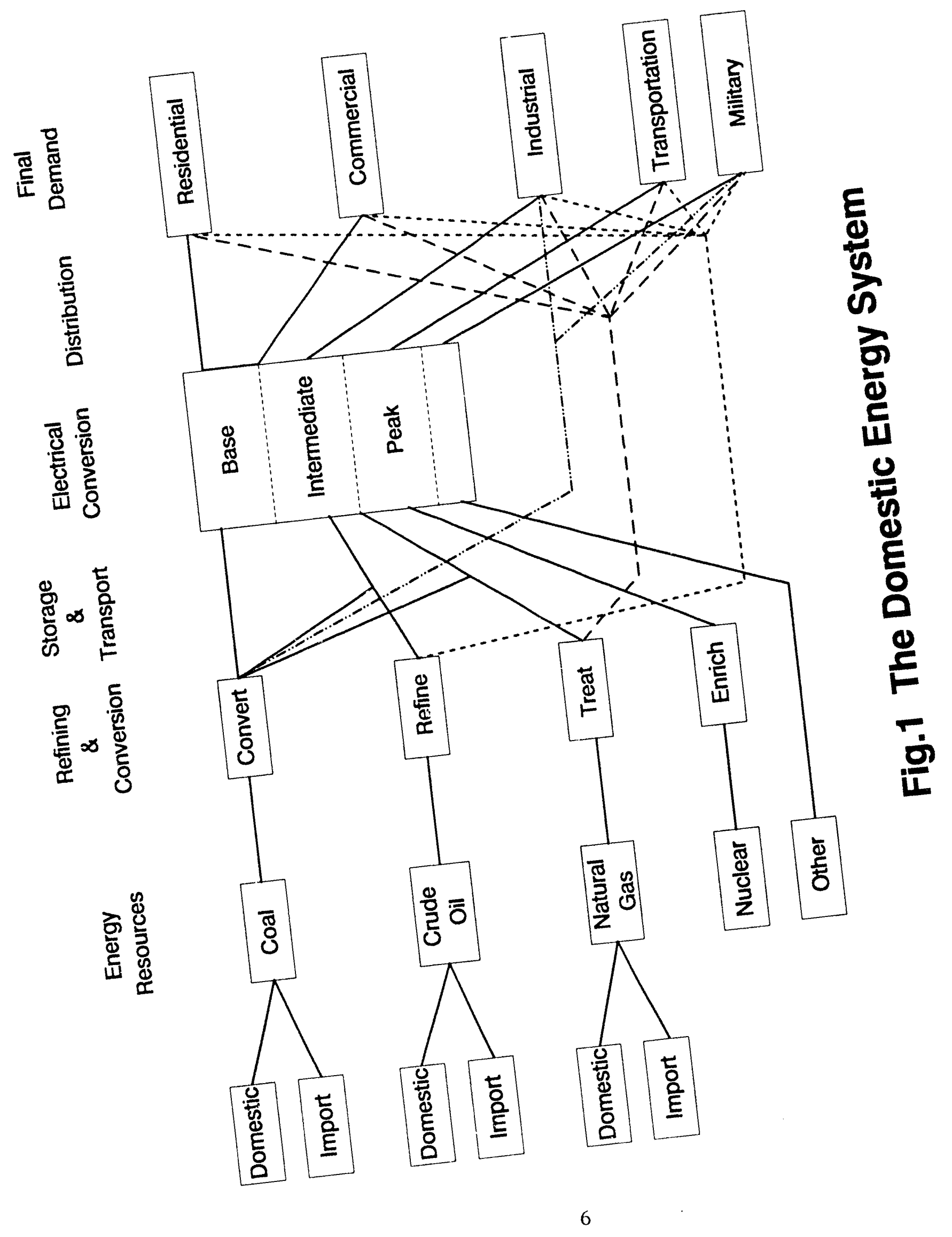


These horizontal movements indicate the linear path energy products follow, from extraction to consumption, and can be used to highlight "softspots" in the energy system. As we discuss below, just what constitutes a softspot is usually not clear cut and is subject to considerable interpretation. Reliance on imported oil may be considered prima facia evidence of vulnerability for some, while others would argue that inherent features of the energy system, such as an integrated world market for crude oil, offset this. Others would state that the existence of a strategic petroleum reserve (SPR) offsets this vulnerability, while stili others would argue that the existence of the SPR largely offsets private inventories that would have been held in its stead. Thus, the concept of vulnerability imbedded in our definition as a severe inability to adjust is subject to debate and ultimately government must serve as the final arbitrator.

However, despite one's view of vulnerability, it is clear that vulnerability is reduced by an increased ability to substitute, albeit at additional cost. Substitution may occur at the left-most side if imported crude oil can be potentially replaced by domestic production or inventories, or at the right-most side where, for example, electricity produced by coal could substitute for oil in home heating. Practically, substitution is limited in the short run by capital rigidities, and by the constraints discussed in the following section, as well as by the marginal costs of energy forms in alternate uses. This leads to our concern for a sudden, rather than gradual, change as a component to our definition of an energy emergency, and an unanticipated rather than an anticipated one. If the change were gradual, one would expect the private sector to accommodate it efficiently, and if it were relatively predictable, the added costs of flexibility would be accepted as a normal part of doing business. Typically, one would look to the government for assistance in extraordinary, rather than ordinary, circumstances.

Each set of activities in Fig. 1 is connected by transportation modes and distribution modes. These may be supertankers, pipelines, trains, barges, or trucks for petroleum products or overhead and underground transmission/distribution networks for electricity. Like production facilities, these are capital intensive and form a unique aspect of the physical vulnerability of the energy system.

Finally, Fig. 1 can be used to indicate the sort of data requirements inherent in vulnerability analysis. Following a path for crude oil from import stage through transport, refining, transport, perhaps electrical generation, and to end use requires a good deal of information. To this must be added data on alternatives and degrees of substitutability. As matters turn to policy analysis, private and social prices must be assessed and compared. Clearly, to do this for each and every potential vulnerability would be costly, so criteria must be developed to judge priorities.

As part of the National Energy Strategy (NES) process, the Department of Energy (DOE) prepared an extensive set of energy projections which could provide a point of departure for analyzing vulnerability. Although these projections are at a fairly aggregate level, they provide a basis for national energy planning. Table 1 displays a few aspects of the energy projections relevant for crude petroleum and petroleum products (oil).

Three fundamental kinds of data can be used to place boundaries on petroleum issues. The upper part of Table 1 contrasts the quantity of oil in final consumption with those of other fuel sources. Oil makes up about 41 percent of energy consumption in 1988 and is projected at about 37 percent in 2010. Projections are based on input assumptions, and changes in these assumptions yield different views of the future. One important assumption in energy analysis is the future cost of oil, and DOE recognizes this uncertainty by offering three projection series based on high, medium, and 
Table 1. Energy consumption by primary fuels (quadrillion Btu)

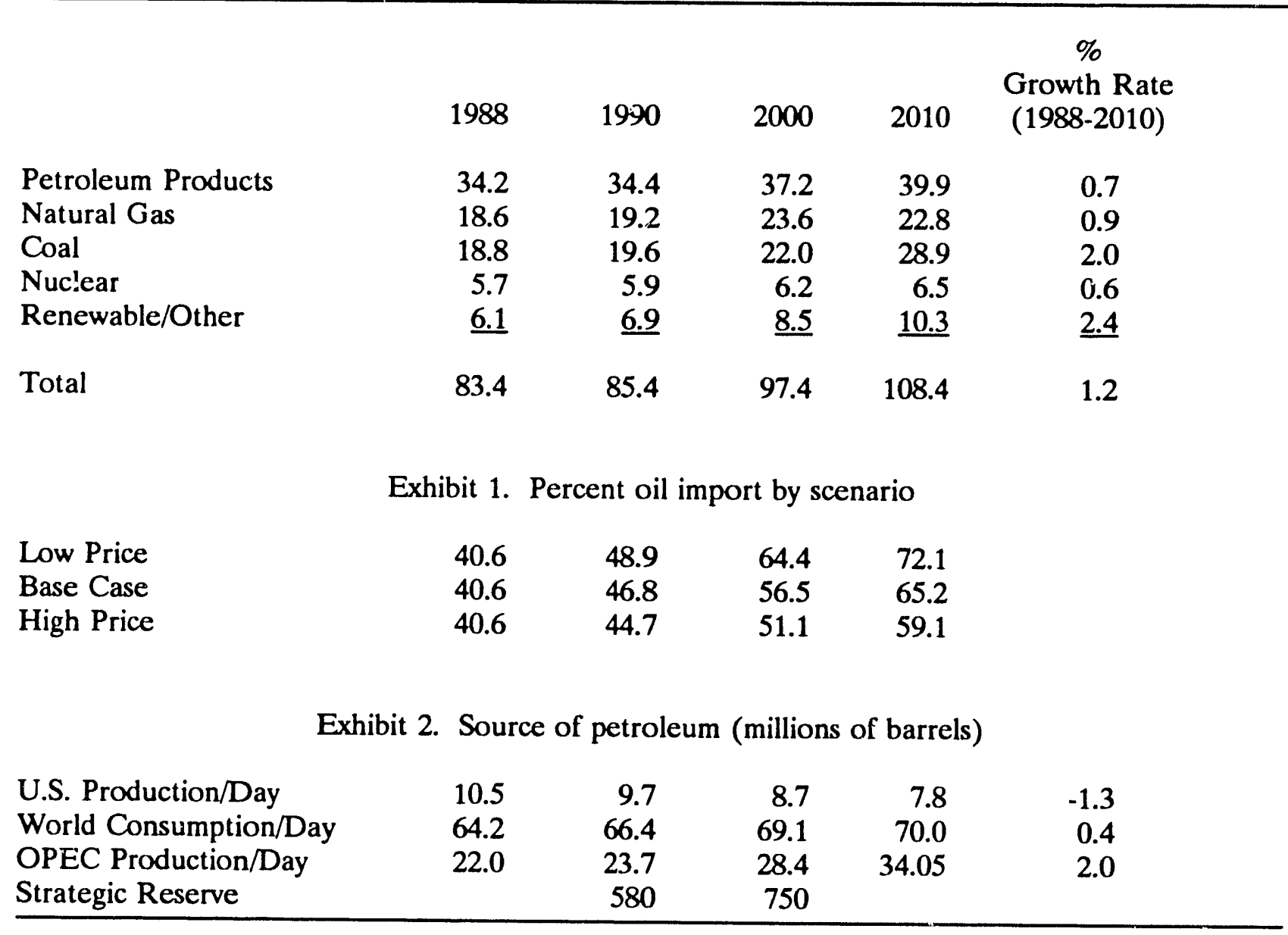

Source: Annual Energy Outlook 1990

DOE/EIA-0383(90) 
low price assumptions, shown on Exhibit 1. Under all price assumptions the share of oil supplied by imports rises, with a range of 60 to 72 percent in 2010 . Whether or not such a change contributes substantially to oil vulnerability is conditioned by many things, for example, the source of the imports and the status of domestic inventories. U.S. production is projected to decline somewhat (under the base scenario), and OPEC production to increase much more rapidly than world consumption as a whole. The U.S. Strategic Petroleum Reserve (SPR) stands at 580 million barrels in 1990 and is expected to increase to 750 in 2000 , or about three months of imports.

These data, with the physical representation of Fig. 1, illustrate the dimensions of oil vulnerability, though they contain only a portion of the data needed to study energy eniergencies. Starting at the left-hand side of Fig. 1, the oil system is primarily susceptible to an import or production disruption or a severe relative price change. Inventories held in the SPR provide the primary public remedy, though, at any point in the flow, one could potentially substitute a cifferent energy form for the reduced or more expensive oil. If substitution does not occur, the adjustment is made at the right-most side in reduced end use. The next important link in the oil sector is refining. Loss of a refinery places additional loads on other refineries and tests the ability of the transportation system. primarily pipelines, to secure the adjustment. Next, soft spots occur in oil-using electrical generation facilities. Here, substitution is possible in the form of electricity from other energy sources. Finally, at end use points, vulnerability can be generated by changes in inventory behavior (hoarding) and relieved by changes in energy use (such as cat pooling). The ability to adjust to breakdowns in the system is conditioned by both physical rigidities (e.g., the ability to use more than one kind of fuel, to increase refining volumes, or the existence of pipelines with excess capacity) and the availability of fuel substitutes. Hence, fur disrupted fuels consumed in large quantities, the sheer availability of fuel substitutes may be an ultimate limitation.

This section has illustrated the physical aspects of the energy system, focusing on oil as a particular source of vulnerability. In the following section, we extend this by examining a taxonomy of emergency types. These place physical constraints in proper perspective with other constraints which contribute to energy emergencies.

\section{TYPES OF ENERGY EMERGENCIES}

The schematic presented in the previous section described the various points at which constraints can occur, how different energy sectors are interrelated, and how emergencies in one energy sector may affect and may be dissipated by other energy sectors. In this section, we discuss the various types of events that may lead to sudden changes in quantity, market price, and/or social value at various points in the energy system. In particular, we examine five types of events -technical constraints, changes in economic structure, changes in external political conditions, shifts in regulatory and institutional constraints, and sudden changes in the externalities associated with the production and/or use of energy. 


\subsection{TECHINICAL, CONSTRAINTS}

Technical constraints occur as a result of the rigidities and fragilities of the capital stock and the technology embedded in it and can occur at any point in the energy system. They occur when oie aspect of the energy system fails and other parts, due to capacity limitations or other constraints, are unable to accommodate the necessary changes. Transportation networks provide a useful example of the interrelatedness of the system. For instance, a crude oil or refined products pipeline failure or a failure in a major electricity transportation network could lead to significant quantity reductions in affected regions, if alternative delivery routes could not be secured. Alternative routes could be made unavailable by a variety of the constraints discussed in this sectinn, from capital capacity to regulation. Technical transportation constraints could be precipitated by i number of causes, for example, natural disasters, terrorism, or a catastrophic failure of the transportation technology -- such as a ruptured pipeline. In the schematic of Fig. 1, direct technical constraints can be approximated as physical limitations, but must ultimately be examined as a market response. As first approximation, one might ask how much production or product is lost through the technical failure. However, complete analysis requires examining the market-driven adjustments that occur as the market reallocated fuels to their highest and best uses, given increases in relative prices.

A technical failure in one part of the system can also be passed along to other parts of the energy system. For example, the failure of a majoi refinery complex or power station in one region leads decision makers in other regions to modify their expectations about the technology's reliability, and the problem may thus be transferred. Similar problems could result from an acknowledged failure of a major developmental energy system. For example, failure of advanced oil recovery technologies could significantly alter the recoverable reserves of petroleum. New technological knowledge or the potential for it can precipitate large price increases or decreases unrelated to current physical energy relationships. The recent "jitters" in energy markets that accompanied the potential for "cold" fusion are suggestive of how market expectations and prices are linked to potentially large changes in technical constraints. These expectational changes in the system are reflected in the subjective premiums that decision makers ado to production costs to reflect uncertainty and risk.

\subsection{CHANGES IN MARKET STRUCTURE}

At each link and node in the energy system, buyers and sellers possess different amounts of market power; that is, they can exert different amounts of influence on the quantities and prices of marketed energy products. These differences in power are described as differences in market structure, i.e., the degree to which the market is competitive, oligopolistic, or monopolistic, and the degree to which the market is regulated. ${ }^{2}$

\footnotetext{
${ }^{2}$ In a competitive market there are many buyers and sellers, none of which is individually large enough to exert control over market prices. In a monopolistic-monopsonistic market, there is only one buyer and one seller, each of which has some control over market prices. In an oligopolistic-oligopsonistic market, there are a few buyers and a few sellers, which vie for and interact over varying and often unstable degrees of market price control.
} 
Each market structure can be analyzed through a corresponding supply and demand structure, which in turn permits predicting the ievel and behavior of market prices and quantities. In the case of a competitive market, the quantity produced and consumed and the equilibrium price are uniquely determined. By contrast, in a bilateral monopoly -- i.e., a monopolist and a monopsonist -- the two sides bargain over quantity and price. The equilibrium price for a particular agreed upon quantity is, however, not uniquely determined and depends on the bargaining power of the two sides. A movement from one market structure to another, which may simply be a change in bargaining power within a noncompetitive market structure, can result in altered market prices. In those cases where the energy resource has a large rent component, the differences in prices can be large. ${ }^{3}$ Changes in market structure can be shown in Fig. 1 as changes in the supply and/or demand curves at the node in which the change occurred. For example, if a supplier gained a degree of market power, an attempt to raise prices might be made. The success of this move, and the distribution of its impacts, is related to the relative market powers of purchasers of the product.

\subsection{CHANGES IN EXTERNAL POLITICAL CONDITIONS}

Decision making agents, particularly national governments, often include non-economic arguments in their objective functions, which can change with changing political conditions. Significant changes in political conditions in countries that are major suppliers or demanders of energy can alter energy quantities produced and consumed and expectations about future energy prices. Political objectives may dictate that actions deviate from those suggested by purely economic conditions.

Supply embargoes and military conflicts are of primary concern. Although the politically motivated oil embargoes of the past two decades have had only negligible effects on the availability of petroleum, the threat of effective embargoes must be considered. Embargoes may also be realistic concerns in other energy markets, such as natural gas. Military conflicts, such as the Iran/Iraq War, pose a more serious concern. War can lead to disruptions of production and/or transportation that can alter quantity supplied and spur the demand for private energy stocks. Sometimes the roles are reversed, as in the United Nations embargo imposed on Iraq following its invasion of Kuwait. In this case, it was largely through the efforts of oil importing countries that an embargo was effected.

Supply disruptions due to political changes are treated in Fig. 1 much like other forms of supply disruption. It is, however, noteworthy that changes in political conditions are highly uncertain and difficult to forecast. When they do occur, the mixed motivations of the participants may trigger significant expectational changes as iisk premiums to account for the new uncertainty are added. For example, the move by Iraq against Kuwait triggered rapid price increases at the gas pumps which were only weakly related to physical changes, but which reflected the increased uncertainty in world oil markets and led to inventory building.

\footnotetext{
${ }^{3}$ The price or cost of any raw material, including energy resources, is composed of two elements -- the cost of extraction and processing and the value of the resource in situ (that is, in the ground). The cost of the resource in situ is often called rent and is a function of the scarcity of the resource. The prices of resources that are not scarce, such as ocean water, contain very small rent components. The prices of resources that are scarce, such as petroleum, carry a large rent component. Changes in the structure of the energy market can significantly alter the availability of resources for production at the current time and/or expectations about future resource availability. These changes in resource scarcity can, in turn, lead to changes in rents and thus changes in energy prices.
} 


\subsection{CHANGES IN REGULATORY AND INSTTTUTIONAL CONSTRAINTS}

Regulatory constraints limit the private sector and possibly government from responding to energy emergencies in three specific ways. First, they place boundaries on economic behavior, in the sense that they proscribe certain types of price and other changes. Because markets provide information and incentives through price changes, the ability of the market to respord can be significantly reduced. Second, regulations provide an economic backdrop against which economic development occurs. Thus, rate of return regulation may influence the type and character of capital stocks, and may provide an expectation that the regulated sector is somehow insulated from energy emergencies. Government involvement in economic sectors that falls short of regulation may also lead to calls for market interference during an emergency. For example, farmers who are highly dependent on liquid petroleum fuels on tight production schedules typically do not stockpile because they believe that in an emergency, fuels will be allocated to their sector. Third, regulations introduce a degree of uncertainty, because they are subject to review and change, often in ways that can lead to abrupt changes in operating environment. Each of these three effects can either cause sudden swings in energy prices or quantities, can set preconditions that make these swings more likely and/or pronounced, or can reduce private incentive for self protection. The general effect of regulations is to reduce flexibility. Reductions in regulations tend to increase flexibility. Thus, oil deregulation and reductions in gas and electricity regulation tend to make the system more resilient to shocks.

Institutional constraints can also lead to sudden and large changes in energy quantity and price. Coal miners, for example, choose contract dates that occur in period of high demand for coal to place additional pressures on mine managers to settle quickly. If talks break down or strikes occur, disruptions are therefore magnified. The potential for these actions, such as an impending contract negotiation, typically also affects expectations about future energy markets and can therefore result in energy price and quantity changes.

\subsection{SUDDEN CHANGES IN EXTERNALITIES ASSOCIATED WITH ENERGY PRODUCTION AND USE}

As was discussed above, energy market prices contain information on the marginal costs of energy resources and other factors of production, on expectations about future conditions, and on self-insurance premiums to promote flexibility. There are also costs, termed externalities, that are not reflected in market prices. An externality can be defined as either a cost or benefit that results from the production or use of a good or service that is borne by individuals or firms not directly involved in either the production or use of that good or service. When an externality exists, the price negotiated for the good or service does not take into consideration the external benefits or costs, and the market price of the good or service does not reflect true social value.

External costs and benefits can take various forms. With respect to energy, two externalities are of particular importance -- external environmental costs associated with the production and/or use of energy, and external military-security benefits derived from the use or the potential use of energy. When environmental externalities or military-security externalities change suddenly and

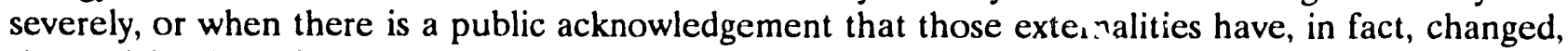
the social value of energy changes. A sharp and sudden change in the social value of energy, in combination with an inability to adjust rapidly to the altered environmental or military-security externalities, can constitute an energy emergency. 
With respect to environmental externalities, an energy emergency is more likely to result from the public acknowledgement that a significant externality exists. The Three-Mile Island incident is an example of public acknowledgement of potential environmental externalities associated with nuclear power. The current controversy about fossil fuels anc the production of carbon dioxide and acid rain is another example. In these cases, the actual externalities associated with the production and use of these energy types did not change. Rathe $i$, new information became available which allowed the public to revise its assessment of associated environmental externalities. This revaluation of potential environmental harm can lead to regulatory actions that either directly limit the quantities of some forms of energy or, alternatively, impose taxes or technological restrictions on the production and use of some types of energy such that energy prices increase sharply and suddenly. The dislocations that result can impose large economic costs. ${ }^{4}$

The social value of energy used or potentially used in military applications, and thus the military-security externality, can change suddenly and drastically if the threat of military actions against the United States or our allies changes suddenly and drastically. The military traditionally recognizes a current state of the world and a series of probablistic states of the world which may escalate toward war. For example, a current state might be typical business as usual conditions; heightened tensions might include political unrest between an ally and an adversary; and a state of war might exist as hostile movements across borders take place. In recognition of these alternative states, the DOD has developed the defense conditions (DEFCONS) and more recently a set of industrial conditions, referred to as the Graduated Mobilization Response (GMR), intended to allow the economy to "ramp up" gradually in the face of a changing state of the world. The value to the military is the expected value of utility from purchases in each of these states multiplied times the probability of that state. Thus, the expected value of fuel is higher to the military than its peacetime market price, with the difference being the military-security externality. This externality, or premium, can change markedly in response to changing world conditions, with little or no affect on market prices. ${ }^{5}$

Finally, some analysts include a third externality, that of information. Because of economies of scale in information collection, individuals frequently undercollect data if left on their own. Also, individuals who do collect data usually have difficulties in appropriating the full benefits of their efforts, i.e., in marketing it so as to recover costs fully. Both of these effects result in the private sector producing a smaller body of data than would be optimal. Other analysts treat information in

\footnotetext{
${ }^{4}$ Economic analysis of external costs, as occur when firms do not pay for environmental cleanup or damage, are generally modelled as a supply premium. In Fig.1, this would be shown as a shift upward at the supply node where the externality occurs. The classical result which comes out of such an analysis is that when external costs are not paid, the market price is too low, resulting in too large a quantity of production. If the firm is required to pay the cost, the supply curve shifts upward, prices rise and output is reduced.

${ }^{5}$ Military-security externalities can be modelled on Fig. 1 as a demand premium, much as environmental externalities can be modelled as a cost premium. Under such an analysis, one might conclude that more energy should be produced at a higher price. However, it is not clear that in the event of a military emergency, the government would choose a market approach to obtaining energy products, i.e., going into the market and bidding up prices. Instead, an allocation approach might be taken, which, during a conflict, could be shown on Fig.1 as a reduction in petroleum product supply available to final purchasers. In response to this reduction, prices would began to rise, energy forms would be substituted for the unavailable petroleum product, and a new market equilibrium would be generated. However, during some periods in U.S. history, such price increases have been deemed unacceptable, and government has chosen to impose allocation systems on the private sector to avoid subjecting certain consumer groups to rapidly rising prices. The impacts of all of this are complex, but could be approached using the format of Fig.1.
} 
However, government is already heavily involved in energy markets, and it may be expected that government will expand its role when emergency conditions arise. In the following section, we examine the options open to the economy for promoting economic goals, the role government can play in this effort, and the tradeoffs that must be recognized between the objectives of emergency policy and othe: government responsibilities, particularly environmental policies. Throughout this discussion, we retain a primary focus on preparation and on economic efficiency, but point out the important role equity considerations play as emergencies actually unfold. 


\section{OPTIONS, TRADEOFFS, AND THE ROLE OF GOVERNMENT IN ENERGY EMERGENCY PLANNING}

The previous section concluded that there are two basic aspects to emergency energy policy - planning and implementation -- that there are two actors -- the private sector and the public sector -- and there are two bases for policy -- equity and efficiency. This section builds on this format by presenting the options open for energy emergency activities, outlining what government can and cannot do, and indicating the nature of policy tradeoffs between energy emergency and other energyrelated goals.

\subsection{MAKING THE ENERGY SYSTEM MORE RESILIENT TO ENERGY EMERGENCIES}

As has been discussed, private producers and purchasers of energy products at each link and node of the energy system carry out transactions that determine the prices and quantities at which these products are traded. In this process private agents form expectations about the likelihood and nature of disturbances that may affect their business environment and make decisions as to "self insurance" to protect themselves. Likewise, the government makes decisions to protect societal interests, such as national defense and economic stability. One aspect of both public and private decisions is to invest in what we have described as flexibility -- the ability to substitute one energy product for another in production or use, thereby overcoming the natural inertia imparted by the system's capital intensity. A second aspect would be to hold larger than normal inventories. These actions add to costs during normal business conditions and reduce costs during emergencies, and result in an increase in efficiency. The private sector would naturally undertake those measures that were in its interest, and the government should undertake those measures that are in society's interest but are ignored by the private sector. In addition, the government can engage in contingency planning which has as its goal a set of institutionalized procedures that override market forces. These could be implemented during war or during other periods of duress.

\subsubsection{FLEXIBILITY ON THE SUPPLY AND DEMAND SIDES}

Planning for and implementing flexibility measures must occur before the onset of an actual energy emergency and have as their objective increasing the efficiency of the energy system, by incurring additional costs while circumstances are normal to reduce costs during an emergency. The difficulty is that expected costs and benefits must be balanced within an extremely complex system in which a variety of governmental and non-governmental programs can distort incentives. Flexibility planning also is predicated on assumptions about the sorts of actions which will be taken by government during an actual emergency. Thus, government contingency plans will be taken into account by the private sector when considering their own flexibility investments. 


\subsubsection{Surge Production Capacity}

Surge production capacity refers to the ability of energy producers to quickly bring on-line additional capacity that would otherwise remain unused. For example, capping oil and natural gas wells that cannot be operated competitively at current prices can be capped in such a way that they could be put into production very quickly if prices escalate. Excess electricity production capacity and transmission capacity are other examples. In general, the capital intensity of the energy system tends to put natural bounds on excess capacity, and these bounds can be overcome only at additional cost.

Although the exact impact of these preparations will differ from application to application, they are essentially producer activitics that increase supply. For example, capping wells will add somewhat to current costs, but will make more crude available at higher costs, than was previously true. $^{6}$ In other instances, more pervasive shifts in costs could occur, as when expensive capital redundancies must be put into place.

\subsubsection{Flexible Production and Transportation Capacities}

Flexible production and transportation capacities refer to the capabilities of the energy system and the economy in general to make adjustments in the transport of energy commodities quickly. These may complement or substitute for surge production capacity depending on the circumstances. For example, a sudden bottleneck in a major oil pipeline on the west coast of the U.S. may call for additional oil to be shipped from the east coast to the west coast. The capabilities of the transportation network to accommodate these changes will determine, in part, the severity of the event. In another example, a disruption in the importation of light, low-sulfur crude may encourage the additional use of heavy, high-sulfur crude. The degree to which existing refinery capacity can accommodate an altered crude mix may be crucial in determining the overall impacts of the event.

\subsubsection{Fuel-Switching Capacity}

Fuel-switching capacity refers to the capabilities of energy consumers to switch from one fucl to another. In a broader sense, fuel-switching capacity can also refer to the potential for substituting other inputs for energy -- i.e., capital, labor, or materials. Should the quantity of a fuel be constrained or the relative price of a fuel increase sharply, fuel-switching capacity allows adjustments to take place more quickly, and economic dislocations to be avoided. This is a demand side measure which essentially reduces the slope of the demand curve for energy at the expense of an increase in the cost of supplying the final energy service.

\footnotetext{
${ }^{6}$ In general, investments in surge capacity increase the cost of current production somewhat, but would make it possible to produce at levels which exceed the capacity that existed prior to the investment. Capacity could be shown as a portion of the firm's supply is fixed, i.e., even at higher prices additional production could not take place rapidly. After the investment, this boundary condition would be moved outward.
} 


\subsubsection{Institutional and Regulatory Fexibility}

To the degree that institutional and regulatory constraints prevent the market from adjusting to sudden changes in quantity and/or prices, the rosts of an energy emergency become more severe. Eliminating or reducing those constraints prior to an energy emergency promotes flexibility in the energy system and can complement other energy-security measures -- i.e., surge-production capacity, flexible production and transportation capacities, and fuel-switching capacity. However, planning to achieve flexibility is far from automatic. For example, regulatory plans for electricity wheeling in the event of an emergency promotes transportation flexibility, whereas allotment schemes to protect preexisting shares may reduce it. The elimination of rigid gas and electricity pricing schemes promotes the use of surge production capacity if the marginal costs of relatively expensive increments of production can be recaptured. Inflexible leng-term contracts for energy may hinder both the surge production of energy as well as the reallocation of available energy resources. Contracts providing for interruptable or reduced service and/or the ability to recontract enhanced flexibility.

\subsubsection{STOCKPILES}

An alternative to preparing to adjust to the new quantity/price conditions imposed during an emergency is to maintain stockpiles or excess inventories of energy products. Cummonly, inventory behavior is a private sector activity, but private stocks may be smaller than socially desirable when there are costs from a disruption that cannot be internalized by the private sector. These external costs give rise to the need for a public stockpile. These stocks can serve two general purposes. First, both public and private stocks can be accumulated during normal time periods and released when a sudden change in energy quantities and/or prices occurs. The additional supplies from stocks can diminish or eliminate a temporary energy price spike associated with a short-term event. Second, the release of stockpiles during an emergency can reduce energy prices and thus facilitate a slower and potentially less costly adjustment path to the new conditions imposed by the emergency. The stockpile may, therefore, allow the energy system to overcome or minimize the effects of temporary emergencies or, alternatively, reduce the cost of adjusting to new and potentially long-term market conditions. Private inventory behavior can follow identical lines, or, by responding after expectations of an emergency are formed, can take the form of hoarding and thus be destabilizing.

Unfortunately, the accumulation and maintenance of a government stockpile imposes costs of various types. Private inventory costs are similar, but are borne by the private sector and result from decisions by a large number of individual agents, who in the aggregate hold larger amounts of stocks than the public sector. Conversely, the existence of a public stockpile reduces the incentive for the private sector to maintain security-related inventories, because expected profits could be wiped out as the release of the national stockpile drives down prices. As with maintaining flexibility, the objective is to balance the expected costs and benefits of the stockpile to arrive at not only the optimal stockpile level as a preparedness measure, but also the optimal implementation mix of measures (inclusive of stocks and adjustment mechanisms) to respond to energy emergencies in a way that does not encourage destabilizing behavior on the part of the private sector. 


\subsubsection{CONTINGENCY PLANNING BY GOVERNMENT}

The measures discussed thus far are planning measures which are predicated on the existence of a freely functioning energy market during an energy emergency. There are also circumstances in which the government implements plans to override the market mechanism to obtain some high priority objective. In these cases, it is typically argued that interruption is justified, because the adjustment costs of price increases override the efficiency gains of a free market. Military mobilization is an example of such a priority need for which the U.S. has developed contingency plans. Mobilization will require the reallocation of resources from the private sector to the public sector, a process that could be accomplished either by purchase (bidding energy away from the private sector) or by allocation. Currently, the DoD and the Federal government are revising plans for mobilization in a transition from the general powers of the Defense Production Act to a more considered transition through the graduated mobilization response (GMR). Under GMR there is a gradual increase in the social value placed on material production which is reflected in reducing regulatory and institutional constraints and increasing the potential command control of the Federal government over the economy. Beyond this general approach, the tools available for military contingency planning are the same as those available to the private sector, e.g., flexibility, surge capacity, inventories, and stockpiles.

One can analyze the impacts of contingency allocations, rather than market allocations, using the national security externality concept developed above. By estimating the probability of conflict, producers or the government could estimate the likely price increases that would occur during a market-based mobilization (shown as a shift in demand) and compare them with a reallocation (shown as a shift in supply).

\subsection{THE GOVERNMENT'S ROLE IN ENERGY EMERGENCIES}

\subsubsection{WHY GOVERNMENT INVOLVEMENT?}

Thus far, we have asserted that there are occasions when government is justified in intervening in market outcomes to improve the efficiency and/or equity with which the energy system performs during emergencies. In this section, we concentrate on criteria for evaluating government interference, with particular emphasis on economic efficiency. As has been suggested above, the private sector is typically credited with generating efficient economic outcomes, provided certain, admittedly restrictive, criteria are met. Much of economic theory is devoted to identifying the particular circumstances in which these criteria are met and efficiency is achieved. It can also be shown that the private sector, operating under these same restrictive conditions, will generate an efficient response to emergencies. Unfortunately, if "market failures" exist, the private sector's response to the threat of energy emergencies is not efficient -- i.e., the private sector will not operate in a way that minimizes total costs, inclusive of social costs. Three market failures are particularly important to the discussion of energy emergencies -- externalities (environmental and military security), failures with respect to information and uncertainty, and monopoly/monopsony (non-competitive) markets. When these breakdowns are present, government intervention to promote energy security -- i.e., actions that reduce the expected cost of sudden changes in energy quantity, prices, and/or social value -- can be argued for on efficiency grounds. 
The second general argument for government involvement in energy emergencies is to deal with equity concerns, that is, to prevent selected subgroups in the economy from bearing disproportionate costs. The critria by which government carries out these activities are somewhat harder to state than the efficiency criteria vecause they are based on value judgements. Moreover, when efficiency is sacrificed in the interest; of equity, equity goals are harder to achieve. Income redistribution is more difficult when lower levels of income prevail.

\subsubsection{Externalities}

Externalities are defined in Section 2.3.5. Externalities constitute a market failure because the market price at which a product is traded, and upon which private sector agents base their decisions, does not take into consideration the external costs or benefits that accrue to individuals or firms whether or not they are directly involved in that transaction. In -ome cases, government intervention is suggested to correct the price of the product, so that the price covers all costs and benefits, inclusive of externalities.

Military-security externalities ocrur when the probability of increasing energy demands to meet national security needs lead to a social berefit function (demand function) for energy that exceeds the private demand function. If producers believe that the government will follow a market-based mobilization, they would increase investments in flexible production techniques or inventories as they perceive changes in this externality. To the extent they believe that forced allocations rather than market allocations will be imposed during a mobilization, they will underinvest, a market failure will occur because of insufficient incentive.

The military security externality is based on events that may or may not occur and can be paid at the time they occur through a large cost increment or in smaller increments in the form of preparedness measures in advance of the events. In fact, virtually each form of market failure which increases vulnerability can be stated in this way, though at the current time information on nonpetroleum vulnerabilities is quite sparse.

\subsubsection{Failures with Respect to Information and Uncertainty}

The second type of market imperiection -- failures with respect to information and uncertainty -- is present to some extent in all markets. Under conceptually-perfect market conditions, all producers and consumers must have perfect information about their markets, or in those cases where perfect information does not exist, all producers and consumers must be able to take actions to protect themselves against the risks that result from the lack of information. There are three general categories of risks -- market, technological, and regulatory. When there is iittle information, when the information available is of poor quality, and when insurance cannot be purchased, a market imperfection exists. In those cases where the poteniial socia! benefits are large, government intervention is, in general, callen for to correct the imperfection by promoting research and development, by facilitating the quality and flow of information, and by providing a stable, consistent, and weil-defined regulatory environment. 
The collection of information is costly, subject to economies of scale, and duplicative, and the full benefits are typically non-appropriable if carried out by individual firms. For many years government has supplied information on energy and energy-related activities that has been used by both private and public decision makers.

Finally, a strong argument can be made that the risks faced by firms contemplating efforts to minimize the effects of sudden changes in energy quantities, prices, and/or social cost are currently large relative to other investments those firms might make. Given that the potential social benefits from making the energy system more resilient to shocks may be large, government has a role to play in reducing these risks either directly or indirectly.

\subsection{Monopsony Power}

Monopsony power occurs when a buyer of a good or service is sufficiently large to have latitude in fixing the price of the good or service. Like monopoly power, which suggests price fixing capabilities on the supply side, monopsony power indicates a market failure. However, unlike the previously mentioned market failures which suggest government involvement to correct or comper:ate for the effects of the failure, monopsony power on the part of the U.S. market is an opportunity to collectively decrease quantity demanded and thus exert downward pressures on world energy prices.

Monopsony power has been linked most often to petroleum markets. Most of us are aware of the monopoly or, more correctly, oligopoly power exercised by DPFC. $h_{y}$ contiulling output, OPEC can partially control the price received for its crude oil and refined products. We are less familiar with the potential collective buying power on the part of large consumers, such as the United States or the OECD. By collectively controlling demand with tariffs, or by providing subsidies to domestic production, large consumers can influence the price they pay. The consumers power to affect prices has been referred to as the "monopsony wedge" or the "buying-power wedge."

Government intervention can be argued for on the basis of collectively reducing demand for imporied energy and therefole reducing the world and thus domestic price of energy. To the extent that lower imports imply less vulnerability to supply disruptions, the exercise of monopsony power can improve energy security. The exercise or threat of exercising monopsony power may also be effective in countering economic and political objectives of producing countries that may lead to sudden changes in energy quantities and/or prices.

\subsubsection{WHAT CAN GOVERNMENT DO?}

In those cases where market failures can be shown to exist, government has a responsibility to deternine whether intervention can improve overall economic efficiency. In Section 3.1 of this report three general methods were described to make the energy system more resilient to sudden changes in energy quantities, prices, and/or social value. Those methods were improving flexibility on the supply and demand sides and stockpiling. Government can promote one or more of these general options either directly (e.g., government stockpiling) or indirectly (e.g., adopting tax or subsidy policies that encourage fuel-switching capacity). While the need for specific actions depends on the particular energy sector and the specific market failures faced by that sector, the following general measures offer a range of potential government programs. 


\subsubsection{Direct Measures}

Government can direcily intervene to provide one or more general measures. The SPR has received the most attention financially and analytically. The need for government stockpiles has been argued for on the basis of the three market failures mentioned in the previous subsection -- i.e., the military security externality, failures with respect to information and uncertainty, and monopsony power. If there is reason to believe that private firms do not take externalities into consideration when making decisions about stock levels, government stockpiles may be used. In addition, stockpiles of individuals are not large enough to exercise monopsony powers. Direct public-sector intervention to coordinate the use of stocks or other measures as a nation or in conjunction with other nations may be called for in certain cases to exercise monopsony powers.

A second use of direct measures occurs when govınment overrides market outcomes to allocate energy products directly to end uses. This could occur as a result of military intervention, or out of a desire to achieve an equity objective. These interventions are usually recorded in contingency plans, such as for mobilization or for such critical energy needs as home heating oil.

Government can also intervene directly to promote flexibility in its own segment of the energy system. Surge production capacity from government reserves, flexible production and transportation capacities, and fuel-switching capacities make the public sector's segment of the total energy system more resilient to energy emergencies. This is particularly important from a military security perspective where firms have little incentive to stockpile, fearing reallocations or price controls during times of conflict.

\subsubsection{Indirect Measures}

In addition to directly providing measures or mandating that the private sector take actions, government can put various indirect incentives in place to encourage appropriate private sector actions. Various tax and subsidy incentives can be used to encourage the accumulation and use of stocks, surge production capacity, flexible production and transportation capacities, and fuel-switching capacities. Private sector decision making can be facilitated by the provision of information by government agencies concerning the probabilities and likely impacts of events that might precipitate an energy emergency. Government sponsored R\&D may provide new technologies that offer greater flexibilities when energy prices and/or quantities change suddenly. The enactment of government regulations that are clear in their purposes and provisions and which allow maximum flexibility in terms of energy flows and relative prices reduces the regulatory risks faced by private sector players.

Another set of indirect measures has to do with the macroeconomic costs of energy emergencies. In some cases, government measures may be needed to address the effects of energy emergencies on aggregate demand. Since wages in the macroeconomy do not adjust instantaneously to changes in energy prices, the adjustment process may involve a period of increased inflation and unemployment. The failure to adjust quickly will result in aggregate output -- i.e., the output of the total economy -- falling short of its long-run potential. It has been argued that discretionary monetary policy, despite its potential impact of worsening inflation, is the most direct and appropriate countermeasure to sudden changes in energy prices. 


\subsubsection{THE LIMITS OF GOVERNMENT ACTIONS}

There is a fundamental limit on the degree to which government actions in response to energy emergencies can reduce overall economic losses. For example, a higher cost of oil cannot be offset for the economy as a whole. In fact, were the market to correctly anticipate the emergency and correctly take ameliorative steps, there would be no need for further government action to achieve efficiency goals. In this sense, the effectiveness of the marketplace sets a limit on the effectiveness of government. Of course, in the pursuit of equity goals government can always act to redistribute the impacts of the emergency. In doing so, it can hold certain groups harmless at the expense of other groups. For the economy as a whole, however, there is always a piper to pay.

There are also two additional concerns for governmental action. First, because the private sector will anticipate and adjust to the risks of potential emergencies, the government must take care not to carry out duplicative actions. To do so is to invite market failure due to lack of incentive. Second, there is a point at which the additional effort of preparing for emergencies is not worth the cost. That is, buying too much security is as wasteful as the losses that result from being unprepared for emergencies. To avoid the risk of excessive preparations, and particularly of duplicating or replacing actions that would be taken by the private sector, it is generally argued that government intervention should be limited to situations where the private sector fails to recognize the risks or fails to act appropriately on those risks. The downside of underpreparing for energy security risks is that it invites calls for direct government action during an emergency that may be ill conceived or inefficient.

\subsection{ENERGY SECURITY AND ENVIRONMENTAL TRADEOFFS}

We have thus far focused on aspects of government intervention in the marketplace that reduce the vulnerability of the economy to an energy emergency. The government also has the responsibility to protect the environment. The conceptual basis for taking government actions to protect the environment is very similar to that which supports taking government actions to improve energy security. In the process of supplying or consuming energy, environmental costs are incurred for which the principal parties are not or cannot be charged. Thus, there exists the classical environmental externality -- the smokestack imposing costs on downwind residents, rather than smokestack cleanup imposing costs on the consumers of the polluter's products. In pursuing either energy security goals or environmental goals, the government must understand whether its actions support or compete with the other goals. Because each results from a failure of the market to behave optimally, each involves costs external to the market. In a sense, the tradeoff between environmental policy goals and national-security policy goals is a tradeoff in external costs.

Environmental impacts can be grouped into four issues: 1) air quality, 2) global climate, 3) waste management, and 4) water availability and quality. Air quality issues deal with the production of, for example, sulfur dioxide, nitrous oxide, volatiles, and carbon monoxide. Typically, these pollutants arise from burning fossil or carbon-based fuels in power stations, factories, home heating units, automobiles, and other activities. Remedies include using less of the energy products, switching to non-polluting fuels, or adopting cleanup measures, such as sequestering pollutants. 
Global climactic energy issues generally fall into two categories: 1) green house gas production that may affect warming, and 2) ozone depletion which may affect the amount and type of solar radiation reaching the Earth. Warming issues generally center on reducing fossil fuel burning, and methane and chloroflorocarbon reduction. Ozone depletion generally centers on reducing production of ozone depleting agents, such as chlorofluorocarbcns.

Waste management issues are typically divided into nuclear and non-nuclear categories. Nuclear waste issues include controlling radioactive by-products throughout the fuel cycle, but particularly for fission products, characterized by long half lives. Non-nuclear waste management runs the gamut from disposing of trapped pollutants to disposing of materials produced during fuel utilization, such as ash.

Water issues are somewhat more diverse than the others, because they consider impacts on water availability, such as water "consumed" in cooling and diverted by hydropower, and water quality of surface and subsurface sources. Water quality issues are linked to proper waste management, but also concern accidental pollution as from petroleum transport.

Many of the environmental/security tradeoffs are relatively subtle. Reducing dependence on imported oil may contribute to oil security, but may increase domestic environmental impacts if import reductions are accompanied by increases in domestic energy production. To the extent that domestic petroleum prices rise as a result of these policies, environmental assaults will be reduced due to reduced consumption. Similarly, tighter electrical generation capacity margins or the retirement of older, dirtier plants may reduce flexibility in the electrical grid, thus decreasing flexibility. Nuclear issues are somewhat more pointed. The nation promotes climactic and energy security goals by increasing reliance on nuclear energy, but places additional pressure on waste management programs.

Some energy options and policies support security and environmental goals. For example, electric vehicles may contribute to fuel flexibility, and may reduce pollution and save oil, depending on the generation source. Similarly, full marginal cost pricing tends to reduce energy use and pollution. Most conservation measures also support both sets of goals, because they reduce the amount of energy consumed and the environmental degradation associated with that consumption.

\subsection{SHOULD GOVERNMENT INTERVENE?}

We can now summarize the complete set of concerns that should guide the role of government in energy emergency policy. There are three situations with which government should concern itself: (1) the emergency preparedness decision making environment, (2) preparedness planning, and (3) implementation of plans and activities during an emergency. The decision making environment affects both the government and private sector. A fundamental requisite for both is adequate information. For the private sector, two modes of operation are relevant. Profit making private firms form expectations about the effects of preparedness plans on profits, which are in turn fed by expectations of the role government will play and the actions it will take during an emergency. Non-profit making (regulated) private firms have less ability to adjust to market forces as reflected by price signals. Government affects the decision making environment by the priorities it places on efficiency and equity goals. These goals, in turn, affect private sector profit expectations. Private firms can operate most efficiently in the absence of uncertainty; hence, government should express its priorities clearly and in advance of preparedness decision making. 
The second situation of concern is preparedness planning, which includes both plans and inventory or flexibility investments. Actions taken by the private sector will be direct. Inventories will be held, fuel switching capability will be purchased, or a justable contracts will be negotiated. In each case, the tradeoff is business-as-usual cost increases against emergency period cost decreases. Government also engages in direct investments, but also takes indirect actions, such as adopting tax policies that encourage behavior or investments favorable to preparedness. Both direct and indirect actions are taken in support of the recognition of market failures. Government also makes contingency plans that would override market forces. These are generally in support of equity goals, because virtually all energy allocations could be achieved using market forces. In particular, there are contingency plans that support mobilization for war which are coordinated through the GMR. Again, government preparedness plans should be communicated to the private sector to reduce uncertainty.

The final situation is the implementation of plans, given an emergency situation. Implementation by the private sector is automatic and market driven. Implementation by government may be automatic and market driven, such as allowing prices to rise, may be direct and discretionary, such as stockpile releases or execution of contingency plans, and may be discretionary and indirect, such as macroeconomic and monetary policies. In general, the goal of the government is to encourage the private sector to assess costs and profit opportunities fully, and to act on these expectations, given advance warning about interference in markets by the government in pursuit of equity goals.

There are a variety of reasons to believe the private sector may not accurately assess the full costs of an energy emergency. To assess the prospects for emergencies the private sector requires information. It may be argued that the private sector is inadequately or inaccurately informed simply because it is costly to gather and assimilate information. Moreover, it may be argued that there are economies of scale in producing information that the government could exploit by centralizing the information collection effort. Thus, it follows that the government could provide better information more efficiently than the decentralized efforts of the private sector. Before actually undertaking this task, however, one needs a better idea of the kinds of information that are missing and whether the government can be expected to fill the gaps. Another issue to be debated is the downside risk of disseminating misleading or erroneous information by the government, which presumably could have serious repercussions when information production is centralized rather than dispersed.

Even though the private sector may have adequate information, it may not have sufficient incentive to act on that information. Of major concern in this regard are expectations about government actions in an emergency. If the private sector believes that the government will step in and allocate eriergy supplies in a shortage, this expectation would dilute private incentives to prepare for a shortage. Similarly, if inventory holders are expected to face barriers in profiting from inventory sales during shortages, because of the political unpopularity of such profits these expectations will reduce incentives to build precautionary inventories. The fact that allocation regulations were imposed in previous energy emergencies, and threatened more recently following the Exxon Valdez disaster, means that there are good reasons for the private sector to hold such expectations. Another example is the reduction in incentives for private investors to build precautionary oil stocks when the government can reduce the profit potential by selling oil from the SPR. These examples illustrate how the government must take into account the effects of policy on private behavior, no matter how defensible the principal objective of that policy, because those responses can mitigate the effectiveness of the policy. This is not to say that the government should eschew intervention in the private sector in an emergency. The competing objectives of government, particularly in balancing efficiency and equity considerations, means that the government will rationally pursue policies that are sometimes mutually inconsistent, with attendant costs. 
A related problem of distorted incentives occurs in regulated industries such as natural gas and electricity. Because of the ability to set prices and seek profits is constrained by the regulatory process rather than by market forces, firms in these industries do not have the normal profit-making incentives to undertake invesiments in emergency preparedness. In this case, the regulatory bodies that have jurisdiction over these decisions have a responsibility to take into account the need for emergency preparedness and to provide the incentives for firms to undertake the necessary actions. This is already done to a limited extent, but state regulatory agencies are inherently local in their perspective about reserve capacity, back-up supplies, and potential changes in demand. There is a need for a broader perspective at the federal level that aggregates across states and takes into account the interactions among them.

The emergency response problem extends beyond the issue of preparedness within regulated industries and includes built-in constraints on flexibility to respond to an emergency. Electricity and natural gas prices, particularly at the retail level, cannot fluctuate in response to changes in market conditions; they are established by regulatory rules and cannot change without a formal review. Yet changes in relative prices are the way in which markets reallocate supplies and demands to address shortages. Since gas and electricity prices are rigid, the burden of adjustments in energy emergencies will fall more heavily on non-regulated energy prices, particularly on petroleum.

Regulation of the natural gas and electricity industries is slowly moving away from a rigid system of pricing rules to one where market forces will play a greater role. This transition should be encouraged, not necessarily with the objective of deregulation, but to increase the flexibility of gas and electric markets to adjust to disruptions of any kind. Still, it is unrealistic to think that the gas and electric industries could be sufficiently deregulated to allow prices to move freely with market forces, or to allow excess profits earned during energy emergencies to be retained by regulated utilities.

Finally, we turn to the question of whether there are economic costs of energy emergencies that are totally ignored by the private sector. Since the private sector will feel the impact of higher prices and foregone consumption caused by any emergency, such costs must arise as a result of a market failure. Along these lines, two kinds of disruption costs are commonly thought to be ignored by the private sector and which may, as a result, lead to insufficient preparedness. The first concerns the feedback effect of changes in energy demand on the price of energy, while the second concerns adjustment problems that arise in non-energy sectors to a change in energy scarcity. Both kinds of costs are likely to arise only in connection with disruptions in the oil market. Discussion of these costs and the policy options to ameliorate them are taken up in the next section. 


\section{COSTS OF PETROLEUM DISRUPTIONS}

Unlike most examples of peacetime energy emergencies, a disruption in the world oil market will have spill-over effects on all other energy markets and potential repercussions on worldwide economic activity. The magnitude of the potential economic costs and the incentive to avoid them are so large that it is appropriate to pay special attention to the problem of oil security and the issues that determine the role for government policy.

Experience with previous oil market disruptions (in 1973, 1979, and 1986) offers some guidance on the nature of the disruption risks and costs, on private responses to risk and uncertainty, and on the appropriate role of government policy. It is useful to summarize some of these observations before turning to the issues that remain to be resolved.

\subsection{LESSONS FROM THE PAST}

First, neither the level of oil imports nor the share of oil imports in domestic consumption is an adequate indicator of the vulnerability of the overall economy to an oil market disruption. Even the massive price shocks of 1973-74 and 1979-80 created balance-of-payments outflows that were small in relation to gross national product, lead to no observable reduction in the level or composition of aggregate demand, and were followed by an increase rather than decrease in the international value of the dollar. That factors other than oil import dependence need to be considered is illustrated by the fact that following the 1979-80 shock the United Kingdom, which was nearly selfsufficient in oil at the time, experienced the deepest recession of all the major industrial countries, while Japan, which is the world's second largest importer and has virtually no domestic oil production, managed to avoid a recession.

Second, oil market disruptions are a worldwide rather than individual country problem; increased scarcity will be distributed through the market to all countries and will be reflected in higher prices (or greater subsidies) to all consumers. Because world supply and demand determine the world price, policies of individual countries intended to stabilize the world price must take into account the actions of other countries. International cooperation can potentially be more effective than independent actions in stabilizing the market, but it must be focused and coordinated to realize this potential.

Third, any one country's vulnerability to the exercise of market power by suppliers is determined by the degree of concentration of total world supply. Diversification of the sources of supply to any one country will not limit its vulnerability to market power, but diversification of total world supply will limit any one country's vulnerability whether it is diversified or not.

Fourth, oil price shocks can be caused by surges in oil demand as well as by reductions in oil supply. The 1973-74 and 1979-80 price shocks were both characterized by massive increases in inventories of petroleum products and relatively minor reductions in the flow of crude oil. In some instances, therefore, policies that curb panic inventory (and hoarding) behavior could be more effective in stabilizing the market than policies that reduce consumption or increase supply. Cognizance must be taken of the fact that markets have evolved in ways that will reduce the likelihood of the kinds of perverse inventory behavior observed in the past will be repeated. The increase in spot market activity, the decline in bilateral trading relationships, and the emergence of futures markets since 1980 should reduce uncertainty that market adjustments can provide greater 
stability in the future compared to the past. These structural changes also imply that future disruptions are not likely to resemble those of the past and that policy should not be aimed at solving yesterday's problems.

Fifth, the quantity of oil demanded is sensitive to changes in the price of oil and, conversely, changes in oil demand can affect the price of oil. Worldwide oil consumption is no higher today than it was in 1979, and the potential for interfuel substitution is substantial compared to earlier years. Consumption has been growing since the collapse of oil prices in 1986, which will eventually lead to higher prices, and in turn slower grcwth in consumption.

Sixth, the role of collective actions by the members of OPEC in controlling oil prices is unclear, though it will probably be less relevant to future policy planning than it was to past planning. While cartel behavior is commonly blamed for past disruptions, the fourth point listed above and the lack of clear evidence that market power was exercised, give a different impression. Conversely, while the cartel is commonly regarded as ineffective in shoring-up prices in the 1980s, the world price was remarkably stable during 1981-1985 in spite of steadily falling consumption, and the sudden decline in the price in January 1986 cannot be explained by any contemporaneous change in underlying supply or demand behavior. Nevertheless, reserves will remain concentrated in OPEC nations, and the potential for future disruptions related to these nations is a risk that emergency planning cannot ignore.

Finally, there is thus no clear evidence to support the argument that the energy price shocks in 1973-74 and 1979-80 were singularly responsible for th $\mathrm{e}$ worldwide recessions in those years though they undoubtedly played a role in initiating them. The absence of substantiating evidence that would explain the energy connection, plus counter evidence such as the Japan experience noted earlier and the absence of an economic boom following the January 1986 collapse of oil prices, suggest at minimum that the story is much more complex. However, the alternative hypothesis that deflationary monetary policy is to blame is consistent with actual experience and may offer a policy remedy.

\subsection{COSTS AND POLICY OPTIONS}

These observations suggest that a number of changes have reduced the potential vulnerability of the domestic and world economies to oil disruptions. These actions are due in part to actions of businesses and governments who have evaluated the costs of past disruptions and have taken actions that would reduce future impacts. However, the evidence suggests that not all potential costs have been fully anticipated. We now turn to an assessment of the two particular costs of a disruption that may be overlooked by the private sector -- the demand-price feedback and macroeconomic dislocations -- and the options available to the government to deal with these costs.

The demand-price feedback effect is relevant in connection with imported energy where the United States has monopsony power in world markets (as explained in Section 6.1.3 above). Individual private importers have no power over the price they pay, but the government can organize the collective buying power of all private importers through policies that reduce oil import demand. The reason such a policy is worth considering is that import supply is particularly inelastic during a supply disruption and a reduction in import demand is correspondingly effective in limiting a price increase. $^{\text {? }}$

\footnotetext{
7The same argument could be applied to any imported commodity in which the United States has market power, but such an approach would not be wise international policy. What makes oil different is the market power of OPEC and the desirability of counteracting that power. However, as noted above, there is a question of whether that power has been exercised so far.
} 
Two of the approaches discussed above may be used to reduce United States oil import demand during a disruption: a reduction in import demand, through a tariff or quota on imports or an excise tax on petroleum products, or an increase in supply by releasing oil from the SPR. Import controls have the undesirable effect of increasing energy scarcity within the United States (while reducing scarcity in world markets) at a time when the price is already high. The benefits of lowering the world price on imports (and consequently reducing income transfers abroad) are often thought to be less than the costs of imposing e\%en higher energy prices on the domestic economy, although there is no hard evidence on this point. Import controls also have the effect of increasing the earnings of the domestic petroleum industry, which opponents regard as unwarranted windfall gains. These transfers could be avoided with an excise tax on petroleum products, which will have the same impact as import controls on import demand and on domestic prices. Excise taxes have an additional degree of flexibility because they can be targeted to individual petroleum products (to reduce regressivity, for example), while the cost of import controls will be spread across all petroleum products.

The option of releasing oil from the SPR, in contrast to demand reducing measures, will lower the world price and the domestic price at the same time. However, the cost of building and maintaining the SPR is large and is carried continuously whether there is an emergency or not. The stand-by cost of demand restraints is, of course, zero, which accounts for the preference of many International Energy Agency (IEA) couniries to live up to their commitments through this option rather than oil stockpiles.

The second category of economic costs that are ignored in private planning for an emergency are losses in GNP because of problems of adjustment throughout the economy that are required by a sudden increase in energy scarcity. To the extent that energy scarcity cannot be offset by releasing oil from storage or by increasing surge production capacity, some loss of output is unavoidable. An increase in energy scarcity, in other words, inevitably reduces the amount of goods and services that can be produced, and no government policy can reverse this fact of life.

At issue is whether there are economic costs that can be avoided and, because they are not addressed in private sector planning, whether they suggest a role for government policy. These costs will take the form of losses in domestic output and employment because of dislocations in non-energy markets caused by energy price shocks. ${ }^{8}$ They may arise from many intermediate causes -- such as a balance of payments adjustments, aggregate deriand adjustments, inflationary adjustments, or production adjustments -- but they all result from the lack of flexibility in the economy to adjust to a change in the way resources are used.

Reallocations in resources from one industry to another are prompted by changes in the relative prices of resources and in the relative prices of the commodities produced by these resources. As energy becomes more expensive, the appropriate mix of energy and other inputs used in production will change. Similarly, the mir of commodities in final consumption will change as a result of the energy-induced changes in their relative prices.

\footnotetext{
${ }^{8}$ To have such a widespread effect, the emergency must have a significant affect on virtually all energy prices and must last for a period longer than a few days or weeks. Other than a severe disruption in the oil market, it is difficult to imagine other kinds of emergencies that would be so important and so pervasive.
} 
These adjustments cannot be accomplished instanta' eously so there is inevitably some slippage in economic productivity as resources are shifted from one use to " nother. Again, some of these transitional losses are unavoidable, and there is nothing the government can do to eliminate them short of preventing the price of energy from rising in the first place.

The adjustment problems can be more serious, however, when institutional features of the economy interfere with flexibility. The most prominent example is the institutional process for setting wages, where adjustments are made infrequently (e.g., once a year) and almost never in the downward direction. Nominal wages are therefore inflexible, and the real cost of labor can be reduced only by inflating the economy.

These conditions present a problem when the price of energy suddenly rises. The immediate effect is a reduction in the use of energy and, because labor and energy are used in combination to produce other goods and services, a corresponding reduction in the productivity of labor. This means that labor costs will tend to exceed the contribution of labor, so that employers will seek ways to reduce these costs. When the option of reducing wages is ruled out, employers are forced to reduce employment. The reduction in employment implies a reduction in production. The loss in output is usually attributed to the initial energy price shock, although it is more directly the result of wage inflexibility.

Similar dislocations can occur because of rigidities in the prices of resources other than energy and because of rigidities in final product prices. The problem is essentially one of a temporary market failure where prices do not function to eliminate excess supplies and demands for resources and commodities. Resources are involuntarily unemployed (i.e., both workers and employers have no options) and commodity shortages and surpluses develop. Eventually prices and wages will adjust to bring markets into equilibrium, but in the meantime the economy could suffer a severe recession.

There are few practical policy options available to the government to deal with this problem. Price flexibility may be enhanced by reducing or removing government regulation of energy and other commodity markets where feasible. There is no feasible way to directly enhance wage flexibility. However, real wages can be depressed by implementing an expansionary monetary policy that inflates the economy. This will reduce the cost of labor and moderate the need for involuntary unemployment. Inflation is not without its drawbacks, however, even discounting its adverse effects on consumers. One problem is that inflation reduces all real wages by the same proportion rather than in relation to the initial decline in productivity for each employer caused by the energy price shock. Consequently, some wage adjustments will be too low and others too high, and another form of inefficiency is imposed on the economy. A second problem is that some wages are automatically adjusted according to changes in the cost of living. In these cases inflation will not reduce the cost of labor and will fail to generate an increase in employment. Finally, inflation tends to redistribute income in ways that often undermine equity goals followed by the government and which reinforce the negative equity effects of rising energy prices.

The only energy policy option that can mitigate the costs of energy price shocks is one which reduces the magnitude of the shock. Obviously, import controls and excise taxes are ruled-out for this purpose because they only make the domestic price shock worse. The remaining options are flexibility and the SPR, about which more is said in the next section. 
It is emphasized that these economic costs of price shocks are not a function of the quantity of oil imports. They are a function of the importance of oil in the economy, whether the source of the oil is imported or domestically produced; the height of the domestic price increase, whether the domestic price is driven by the world price or by energy policy; and the extent of wage and price rigidity in the economy, which has little to do with the energy sector at all. These observations may help to explain why some countries avoided a recession in 1979 and others did not, regardless of their dependence on oil imports.

Finally, it should be emphasized that research has not yet determined how important the dislocations described above are in determining overall economic performance. Hypotheses to explain the linkage between energy price shocks and the economy have been developed, but have provided fairly weak measures of the importance of the connection. Consequently, we cannot say whether the recessions experienced during the 1970 s could have been averted simply by following a more inflationary monetary policy, or whether an aggressive attempt to lower the price by releasing oil from the SPR would have been required.' Certainly, this is an area that deserves more research, for the answer is important to the debate over the proper size of the SPR and how it should be used.

\subsection{ISSUES CONCERNING THE SIZE AND USE OF THE SPR}

Many studies have been conducted of the optimal size of the SPR, all of which compare the purported benefits of releasing oil in a disruption to the costs of building and maintaining the reserve. Measures of the benefits are all derived from assumptions about the effectiveness of SPR releases in reducing the world price of oil and assumptions about the economic costs that are avoided by lowering the price. Both sets of assumptions are subject to considerable uncertainty, particularly in view of questions about the macroeconomic disruption costs noted above.

One consideration that is not always included in these calculations is the negative effect of the SPR on private stockholding behavior. Private stockholders will build stocks in excess of normal working requirements as long as the expected profit from price appreciation exceeds the additional cost of storage. The SPR will reduce private storage incentives by reducing expected profits. Thus, estimates of the optimal size of the SPR must take into account the replacement of private stocks.

The current volume of private inventories that may have been displaced by the SPR is unknown. Moreover, that effect can vary over time, depending on how the SPR is used. For example, a demonstrated willingness to use the SPR to dampen local and relatively minor fluctuations in the market will displace more private stocks than a policy of using the SPR only for major international disruptions.

\footnotetext{
${ }^{9} \mathrm{At}$ issue is the impact of oil price increases on potential economic capacity. Macro economic polices seck to close the gap between actual and potential GNP, but cannot in the short run overcome decreases in potential economic capacity caused by the higher oil prices. All of this is conditioned by the structure of the economy and its economic health at the onset of the oil emergency.
} 
Interactions between the SPR and private stocks also play a role in determining the effectiveness of the SPR in reducing the price of oil. If private stocks are released concurrently with a drawdown of the SPR, the two flows will complement each other in affecting the world price. Conversely, private stockbuilding can absorb oil released from the SPR and reduce its effectiveness in stabilizing the price. How SPR release might affect private behavior will depend on a variety of influences, many of which have not been studied. As noted in the next section, the scope of the investigation must be broadened to include private and public responses in other countries as well.

With regard to decisions about the drawdown of the SPR, two questions continue to be deiated: when to drawdown and how to time the drawdown rate. The debate about when to use the SPR seeks to balance concerns that it will not be used soon enough or often enough, because of lags in administrative decision maki.'o, and concerns that it may be used too quickly and too frequently, because of the limit on refilling salt domes, the adverse effect on private incentives to hold stocks, and the risk that the reserve may be prematurely depleted. Rapid release is recommended by those who view disruptions as self-generating phenomenon that should be quelled before they get out-ofhand, while a cautious wait-and-see approach is recommended by those who are less certain of the dynamics of disruptions and wish to avoid premature exhaustion of the SPR.

Mechanisms have been proposed to trigger the release of SPR oil, such as the sale of options to purchase SPR oil at a predetermined strike price. By setting the number of options to be sold over a range of strike prices, moreover, the government would be establishing the minimum drawdown rate as the oil price rises above each threshold. How to set this rate is difficult to determine in the abstract, however. As a practical matter the decision will likely hinge on the way the emergency develops.

\subsection{THE IMPORTANCE OF INTERNATIONAL COOPERATION}

The role of the International Energy Agency (IEA) is a potentially important but often discounted facet of U.S. energy policy. The IEA is important because cooperation will make any one country's attempt to stabilize the market more effective, and it is often discounted because adequate and timely cooperation are thought to be an unattainable goal. However, cooperation may prove to be the only effective way to control oil price shocks, so that securing cooperation could be as important as building the SPR itself.

To understand the importance of cooperation, it is useful to delve deeper into how the SPR may be expected to control oil price shocks. The issue is not as simple as comparing the maximum drawdown rate of the SPR with the expected reduction in supply to determine the probable shortage. As observed earlier, an important feature of past disruptions is the considerable volume of private inventory building and hoarding that accompanied relatively minor reductions in supply. These are the responses of risk averse individuals who may or may not be placated by a release of up to 3 million barrels per day from the SPR.

The magnitude of potential stock building around the world is staggering. The only official inventory data are for stocks held by refiners and distributors in OECD countries, which fluctuated by hundreds of millions of barrels over a few months during both 1974 and 1979. In 1985 these stocks amounted to 3.5 billion barrels, so that an increase by only 10 percent in response to disruption risk amounts to 350 million barrels, about 117 days maximum drawdown of the SPR. This does not 
count stockholders in non-OECD countr es, nor stockbuilding by consumers with storage capacity. Even though stock building is a temporary phenomenon that may last only a few weeks or months, the destabilizing effect on price can take longer to work itself out. In the meantime, economic damage can be done.

This reasoning suggests that the contribution of the SPR to price stability may be determined less by replacing a reduction in the flow of crude oil coming into the market than by forestalling the flow of oil leaving the market to satisfy the fears of risk averse suppliers and consumers. There is, of course, a great deal of uncertainty in this chain of argument, including the warning given above that, because of structural changes in the market, future disruptions may not mimic those of the past. Considerably more research is required to assess the uncertainties.

The importance of international cooperation in energy policy becomes apparent when it is accepted that oil market disruptions are a worldwide phenomenon and that individual countries can achieve domestic stability only to the extent that their policies contribute to international stability. That is, the SPR will stabilize U.S. oil prices only to the extent that it helps to stabilize world oil prices.

The reactions of other governments during a disruption can reduce or reinforce the effectiveness of drawdown in the SPR. On one extreme are the kinds of responses that will encourage larger imports and in the process absorb a share of the SPR. On the other extreme are perfectly coordinated policies that are timed to achieve the maximum effect on private expectations in order to forestall a price shock. In between these extremes are mixes of uncoordinated and neutral responses that, even to the extent that they are not offsetting, are less effective in stabilizing the market because their impacts are distributed over time rather than concentrated.

These considerations are of course well accepted by the members of the IEA, though perhaps not with the sense of importance conveyed by the panic stockbuilding scenario described above. The essence of the IEA agreement is the commitment by member countries to reduce import demand during a recognized disruption by either constraining consumption or by releasing stocks. The United States has expressed regret that several countries have chosen the demand reduction option, in part because of skepticism that effective actions are costly (as described above) and politically unpopular, and hence may be compromised at a critical time.

There is also a problem of "free riding" in the agreement where the expectation that some countries will not do their share causes all countries to do less than they otherwise would. In these circumstances, countries must provide meaningful assurances to each other that they will live up to their end of the agreement. Stockbuilding in advance of a disruption, because it is a positive and expensive action, gives other countries the assurance that the commitment will be honored, while a promise to constrain demand does not. This deficiency must be overcome in order for all parties to regard the agreement as a serious commitment by which they all will abide. 


\section{RELEVANCE FOR THE OFFICE OF ENERGY EMERGENCIES}

\subsection{SUMMARY}

Thus far, we have focused on the general concept of energy emergencies and on the issues government must tace in developing policies to deal with emergencies. These concepts and some of their implications have been illustrated for the case of imported oil. We now turn to a discussion of the relevance of these findings for the OEE.

In brief summary, our assessment suggests that there are several components to policies for energy emergencies. We define an energy emergency to be a rapid shift in the quantity, market price, and/or social value of energy coupled with an inability of supply and demand systems to respond satisfactorily to the shift. Without advance preparation, some needs served by energy may go unmet or may be met at unnecessarily high prices. A variety of advance preparations are available, many of which can be undertaken by either the private or the public sector. Complicating the situation is the pervasiveness of energy in our everyday lives, the interrelatedness of the components of the energy system, anci ihe potential for energy emergencies to concentrate burdens in ways that society may regard as unfair. Finally, energy plays a vital role in our defense effort, and whether or not an active conflict is underway, the potential value of inergy applied to this purpose makes supplying the military effort a matter of vital concern. There are a number of reasons why the private sector may not respond fully to needs for emergency preparation. When the private sector does not respond appropriately, there is reason for the government to step in and make these preparations.

Government pursues two goals in making a decision to intervene in the energy system. In assessing whether or not the private sector properly balances the certain costs of current prepartory expenditures against the uncer ${ }^{+}$in costs of a potential energy emergency, government pursues an efficiency goal. In doing so, it seeks to assist the private sector in providing the greatest value of goods at the least cost. Government also pursues an equity goal. In doing this, it seeks to ensure that individual groups within the economy do not bear excessive or untenable turdens during an energy emergency.

In pursuing these goals, government should consider three aspects of planning and implementing preparedness measures. First, it can affect the private sector's decision making environment by providing data on energy conditions and information and analyses about changes in trends that could presage an energy em,ergency. It can also provide information on its own policies and how they will be implemented, which will in turn reduce uncertainty in private sector planning. Second, government can undertake preparedness planning and analysis of direct and indirect policy measures. In doing these, government first determines the degree of preparedness undertaken by businesses and consumers, evaluates the adequacy of these actions and, if it finds them inadequate, considers its own options relative to its goals. Third, government can implement preparedness plans, either through fiat or through markets. Measures currently in place include filling and drawing down the SPR and preparing GMR contingency plans, but could also include various taxes, tariffs, and subsidies intended to pay security premiums in advance. In general, it supports the cause of efficiency when it allows rising prices to allocate scarce fuel commodities, and it supports equity when it provides direct allocations on the basis of perceived need. 
Nevertheless, there are significant limitations to what government can accomplish. From an efficiency perspective, the government cannot "overcome" the costs of an emergency any more completely than can the private sector -- it can merely step into an unfulfilled role. Government can, however, reallocate existing energy stocks to meet security or equity goals. From the perspective of consumers, moves to share the burdens of an energy emergency more equitably appear as zero-sum transfers -- for every beneficiary there must be a benefactor. However, for the economy as a whole efficiency is compromised, and losses exceed gains.

There are very real costs to preparing for an energy emergency, which include the costs of preparedness, whether taken by the public or private sector; the costs of duplication, when government spends dollars for purposes already dealt with by the private sector; and the costs of over preparing. Doliars spent on energy emargency preparedness, public or private, compete with dollars that have many alternative sses. Allocations which override market outcomes, whether for security or equity purposes, also entail costs and create disincentives for the private sector to prepare.

However, there are also very real costs to being underprepared. Thus, despite these limitations, there is general agreement that government must participate to some degree in each of the three arenas. The Office of Energy Emergencies is a primary mechanism for DOE to do this.

\subsection{THE ROLE OF THE OEE}

The authority for the Federal government to participate in energy emergency preparedness activities derives from a diverse body of legislation, including the Defense Production Act of 1950 (and amendments), the Trade Expansion Act of 1962, the Energy Policy and Conservation Act of 1975, the Emergency Energy Conservation Act of 1979, the Energy Security Act of 1980, and the Energy Emergency Preparedness Act of 1982. Based on this authority, the President has delegated responsibility for energy preparedness through a series of Executive Memoranda and Executive Orders. In particular, Executive Order 1149 (1969) provided for the delegation of preparedness functions of all kinds to Federal agencies, E.O. 12127 (1979) reorganized the overall Federal preparedness effort under the Federal Emergency Management Agency, and E.O. 12656 (1987) updated the delegation of responsibilities.

Within DOE, the Secretary has delegated responsibilities for preparedness functions for energy emergencies to the Assistant Secretary for International Affairs and Energy Emergencies and has set out a general agenda for emergency management in DOE Order 5500.1 A (1987). Energy Emergency activities are organized under a Deputy Assistant Secretary for Energy Emergencies, to whom three Offices report: the Office of Energy Emergency Operations, the Office of Energy Emergency Plans and Integration, and the Office of Energy Emergency Policy and Evaluation. In general, the Operations Office carries out the bulk of staff functions, with effort devoted to the vulnerability, mobilization and continuity of government, intergovernmental liaison, and operations support. A major aspect of operations support is the maintenance and operation of the Energy Emergency Management System (EEMS). This system monitors a variety of energy-related links and nodes (generally those shown in Fig. 1), reports on impending or actual energy emergencies, and provides situation reports to decision makers if the need for action arises. The Plans and Integration Office is primarily responsible for exercises, and the Policy Office deals in matters of policy, particularly regarding international oil markets. 
It is possible to divide OEE activities into the decision making environment/preparation planning and analysis/implementation framework developed above. A major aspect of OEE activities falls into the decision environment realm, largely through the provision of information. Within DOE, OEE serves as a source of information on emergency matters. It has developed the EEMS system which draws upon data sources to highlight emergency situations and disseminates these data to the remainder of DOE. Outside of DOE, OEE serves as a point of contact for agencies of government concerned with emergencies that energy may either affect or be affected by. For practical purposes, these are the DoD, FEMA, and the states.

In its preparedness planning and analysis role OEE serves as intergovernmental liaison for emergency matters, particularly reviewing state energy emergency plans. It conducts studies and exercises to test plans related to military energy security. It also conducts analysis related to world oil markets and the SPR. OEE is responsible for administrating the GMR within DOE and participates in the administration of several DoD and FEMA programs. OEE, however, has little responsibility within DOE for the direct implementation of preparedness plans, though a good deal of its preparedness planning and analysis activities serve as a guide to action by others.

\subsection{IMPLICATIONS FOR OEE PLANNING}

The assessment in the body of this report has emphasized the interrelatedness of the energy system, the interrelatedness of DOE goals regarding efficiency, environmental protection, and energy security, and the importance of the private sector as a participant in energy emergency planning through normal market processes. The review of OEE activities indicated the outward looking nature of the OEE, particularly toward DoD and FEMA, and noted a concern with matters of military security. Several other roles are open to the Office which it should consider:

1. Expanding analytical activities regarding energy vulnerabilities of all kinds and integrating into its analyses the role of the private sector in overcoming energy emergencies;

2. acting as an energy security advocate within DOE by tracking R\&D and policy initiatives by other offices and evaluating their impacts on energy security; and

3. becoming a stronger point of contact for other governmental or private groups sceking DOE data or technical expertise on matters of energy security.

In adopting these roles OEE would assume several new responsibilities. It would seek to direct overall DOE efforts at monitoring the successes and failures of private sector preparedness planning. It would critique EIA data collection efforts and models and work to see that the information and tools were available to carry out appropriate analysis. In doing this it would monitor the state of current knowledge regarding policy options for energy security and seek to address critical gaps in understanding. Having done these things, it would become a stronger source of counsel to policy makers. 
One obstacle to OEE stepping into this role is its lack of a common framework for integrating different energy security issues and comparing them to other policy issues within and without DOE. Such a framework would build upon OEE's considerable expertise in preparedness planning and policy, but would create a systematic approach for this sort of economic analysis. The approach would center on government actions as complements to private sector actions and would weigh efficiency criteria as heavily as equity criteria. Elements of such a framework have been raised throughout this report, but a complete statement lies well beyond the scope of the current effort.

That such a framework has not been spontaneously forthcoming is hardly surprising, given the inherent difficulty of the task and the lack of precedents in agencies of government with similar missions. To do so would require providing a common basis for dealing with the public and private sectors, the decision environment/planning and analysis/implementation phases and contrasting efficiency and equity goals. It would also provide impetus to shift OEE's focus toward planning and analysis in light of economic efficiency criteria. Such a framework would be of considerable utility in helping OEE rethink its role within DOE. 
1-10. D. J. Bjornstad

11"13. K R. Ballew

14. D. R. Baumgardner

15. B. L. Bush

16. J. B. Cannon

17. C. V Chester

18-22. T. R. Curlee

23. P. S. Gillis

24. D. L. Greene

25. L. J. Hill

26. E. L. Hillsman

27. M. S. Hubbard

28. C. R. Kerley

29. M. A. Kuliasha
30. R. M. Lee

31. P. N. Leiby

32. V. C. Mei

33. R. D. Perlack

34. B. E. Peterson

35. D. E. Reichle

36. R. B. Shelton

37. D. P. Vogt

38. T. J. Wilbanks

39. P. D. Witcher

40. ORNL Patent Office

41. Central Research Library

42. Document Reference Section

43-46. Laboratory Records

47. Laboratory Records-RC

\section{EXTERNAL DISTRIBUTION}

48-57. Douglas R. Bohi, Resources for the Future, 1616 P Street N.W., Washington, D.C. 20036

58. B. G. Buchanan, Computer Science Department, University of Pittsburgh, 206 Mineral Industries Building, Pittsburgh, PA 15260

59-84. Glenn Coplon, Department of Energy, IE-24, 8F-055 Forrestal Building, 1000 Independence Avenue S.W., Washington, D.C. 20585

85. J. J. Cuttica, Vice President, End Use, Research and Development, Gas Research Institute, 8600 W. Bryn Mawr Avenue, Chicago, IL 60631

86. Douglas R. Hale, Department of Energy, EI-72, 2F-081 Forrestal Building, 1000 Independence Avenue S.W., Washington, D.C. 20585

87. Abraham Haspel, Department of Energy, PE-2, 7H-056 Forrestal Building, 1000 Independence Avenue S.W., Washington, D.C. 20585

88. A. Hirsch, Vice President, Environmental Sciences and Director, Washington Operations, Midwest Research Institute, 5109 Leesburg Pike, Suite 414, Falls Church, VA 22041

89. D. E. Morrison, 333 Oxford Road, East Lansing, MI 48823 
90. Dennis K. Taille, Department of Energy, IE-24, 8F-073 Forrestal Building, 1000 Independence Avenue S.W., Washington, D.C. 20585

91. Alan Simmons, Department of Energy, IE-24, 8F-055 Forrestal Building, 1000 Independence Avenue S.W., Washington, D.C. 20585

92. M. Williams, Professor, Department of Economics, Northern Illinois University, DeKalb, IL 60115

93. Office of Assistant Manager for Energy Research and Development, DOE-OR , P.O. Box 2008, Oak Ridge, TN 37831-6269

94-103. OSTI, U.S. Department of Energy, P.O. Box 62, Oak Ridge, TN 37831 

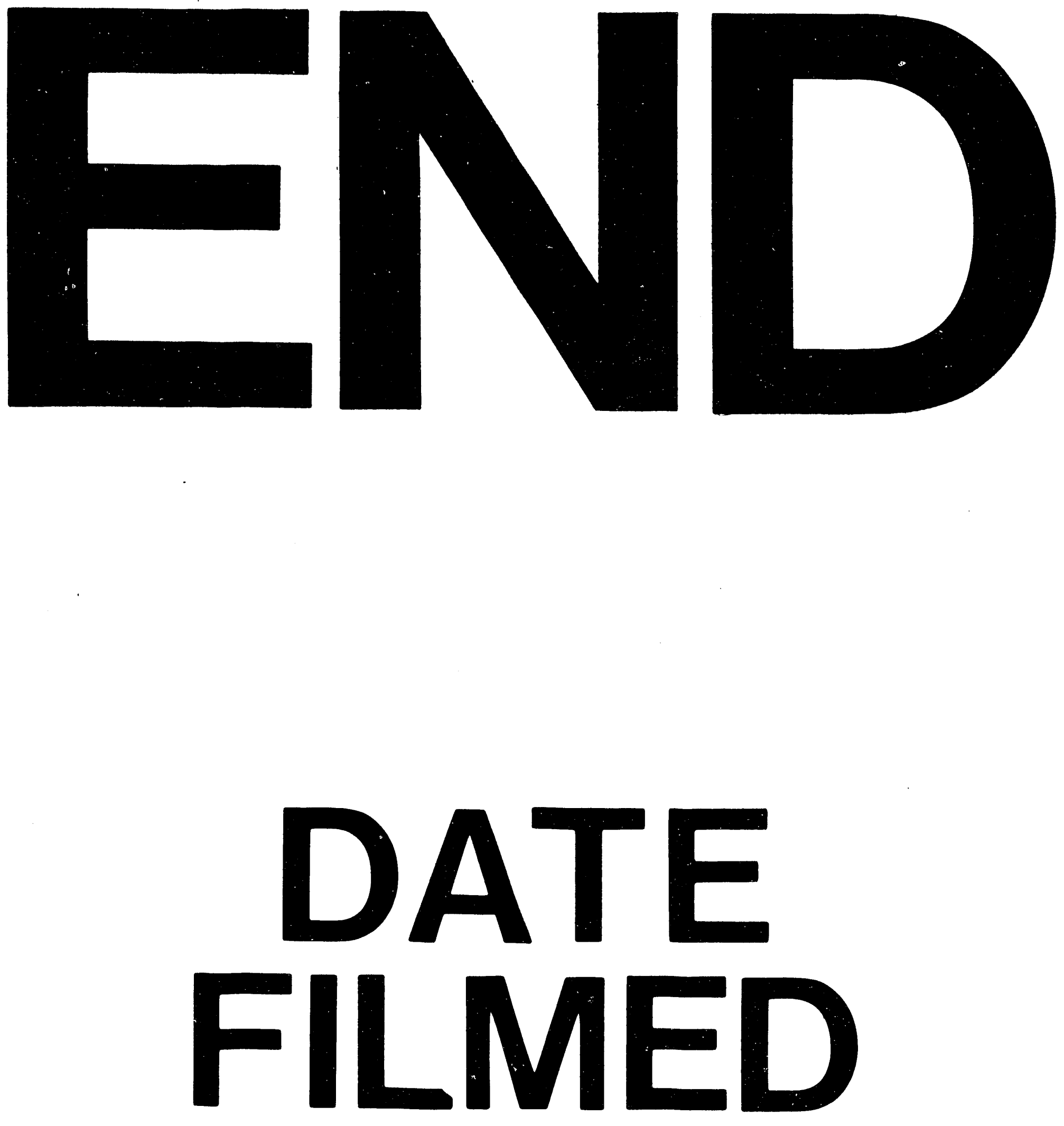

1

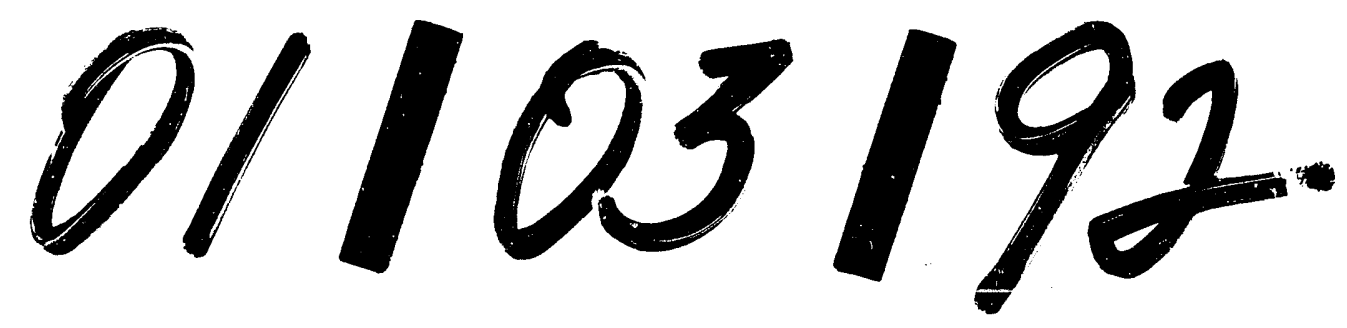

$\longrightarrow 5$ 
